\title{
Métodos de aplicação da simulação computacional em edifícios naturalmente ventilados no clima quente e úmido
}

\author{
Methods for applying computer simulation in naturally \\ ventilated building in hot-humid climate
}

Sileno Cirne Trindade

Superintendência de Infraestrutura Uinversidde Federal do Rio Grande do Norte

Campus Universitário Lagoa

Nova, Caixa Postal 1524 Natal - RN - Brasil CEP 59072-970

Tel.: (84) 3215-3162 E-mail: silenocirne@gmail.com

Aldomar Pedrini Departamento de Arquitetura e Urbanismo, Centro Tecnológico Universidade Federal do Rio Grande do Norte

Tel.: (84) 3215-3722

E-mail: apedrini@ufrnet.br

Raimundo Nonato

Calazans Duarte

Unidade Acadêmica de

Engenharia Mecânica

Universidade Federal de

Campina Grande

Rua Aprigio Veloso, 882, Bairro Universitário

Campina Grande - PB - Brasil CEP 58429-140

Tel.: (83) 2101-1000 E-mail:

rnduarte@dem.ufcg.edu.br

Recebido em 19/02/10

$\Delta$ roitn am 23/nR/1n

\section{Sileno Cirne Trindade \\ Aldomar Pedrini \\ Raimundo Nonato Calazans Duarte}

Resumo

ventilação natural é o principal recurso passivo para a obtenção do conforto térmico em climas quentes e úmidos, reduzindo também o consumo energético com condicionamento artificial. Entretanto, arquitetos fazem restrição a seu uso por não haver garantias de solução dos problemas de conforto térmico, quando comparada aos sistemas artificiais. Nesse sentido, decidiu-se investigar formas de prever o comportamento da ventilação natural em edifícios através de ferramentas de simulação computacional, visando apoiar a tomada de decisão no projeto de arquitetura. O objeto de estudo é o edifício pré-fabricado, do tipo galpão, considerado como típico na cidade de Natal, RN. Utilizaram-se um programa de dinâmica de fluidos computacional (CFD) e um de simulação térmica e energética de edificações. O artigo tem como foco a discussão dos procedimentos necessários para viabilizar as análises da ventilação, indicando como o método teve de ser adequado à complexidade de sucessivas abordagens, resultando em simplificações e incertezas de resultados. Para exemplificar a abordagem apresentam-se alguns resultados de simulações. Ao final, as limitações e potencialidades do método são discutidas com base nas características dos códigos de simulações utilizados, das condições de simulação e da representatividade dos modelos.

Palavras-chave: Ventilação natural. Simulação computacional. Projeto arquitetônico.

\section{Abstract}

Natural air ventilation is the most important passive strategy to provide thermal comfort in hot-humid climates, also promoting a reduction in energy consumption on air-conditioning. However, architects tend to resist using it because it is a less reliable solution for thermal comfort problems than air conditioning systems in conventional buildings. Hence, the aim of this study is to investigate ways to predict the performance of natural ventilation in buildings, using computer-modelling tools to support decision making in architectural design. A typical pre-fabricated building of the City of Natal, State Rio Grande do Norte, Brazil. The study emphasized the use of a computational fluid dynamics software to simulate the airflow outside and inside the building, and a thermal and energy simulation program. The article focuses on a discussion of the procedures required to allow the analysis of natural air ventilation, showing how the method had to be adjusted to the complexity of different approaches, leading to simplification and compromising the reliability of results. Some results of the simulations are presented in order to illustrate the approach. Finally, the limitations and potential advantages of the method are discussed, based on the characteristics of the simulation codes used, the simulation conditions and the representativeness of the models.

Keywords: Natural ventilation. Computer simulation. Architectural design. 


\section{Introdução}

A adequação da arquitetura ao clima ganhou maior importância nos últimos anos, sobretudo devido às preocupações com a eficiência energética das edificações. Entre os recursos bioclimáticos adotados para esse fim, destaca-se a ventilação natural como o principal meio de obtenção do conforto térmico no clima quente e úmido, contribuindo também para diminuir a necessidade de condicionamento artificial. Apesar do grande potencial desse recurso, existem restrições por parte dos arquitetos em utilizá-lo, devido, entre outras, à falta de garantias de que ele possa gerar o conforto térmico necessário, se comparado aos sistemas artificiais de climatização.

Nesse sentido, o uso da simulação computacional como ferramenta de auxílio ao projeto vem se consolidando como uma alternativa viável, porém acessível apenas a grupos de pesquisa de pequeno e médio portes. Esses programas ainda são praticamente desconhecidos da grande maioria dos projetistas atuantes no Brasil, uma vez que requerem para seu uso conhecimentos pouco difundidos na formação de arquitetos. Em países desenvolvidos, os grandes escritórios têm maiores possibilidades de uso dessas ferramentas, pois conseguem envolver equipes multidisciplinares para projetos de grande porte, ao contrário dos pequenos escritórios (PEDRINI; SZOKOLAY, 2005).

Entre os programas de simulação voltados à edificação destacam-se os de desempenho térmico e energético, bem como os de predição da ventilação, baseados na dinâmica dos fluidos computacional, ou CFD. As ferramentas de simulação da ventilação estão entre os programas mais complexos de operação, uma vez que exigem conhecimentos de mecânica de fluidos e de solução numérica de equações diferenciais. Augenbroe (2001) e Maliska (2001) defendem uma melhoria na interface dos programas de CFD para que os arquitetos possam ser incluídos entre os usuários dessas ferramentas, incorporando-as ao processo projetual. No entanto, no estágio atual em que se encontra a simulação computacional, frequentemente é necessária uma equipe multidisciplinar para viabilizar seu uso. Ainda assim, o alto custo de consultoria restringe sua difusão (PEDRINI, 2003).

Em síntese, por mais que programas de simulação da ventilação natural tenham-se tornado acessíveis para a pesquisa científica, questiona-se seu uso por parte do arquiteto, ainda que esse profissional seja o responsável pelas decisões mais influentes sobre o desempenho da ventilação na arquitetura.

\section{Programas de simulação térmica e energética}

Os programas de simulação energética calculam as complexas inter-relações entre a edificação, o ambiente externo e seus sistemas prediais. São capazes de predizer o desempenho da envoltória e dos sistemas de condicionamento artificial, as cargas de resfriamento e aquecimento, e o consumo energético. São algoritmos que modelam os balanços de energia e transferência de calor entre as superfícies da edificação (ZHAI; CHEN, 2001).

Existem diversos programas de simulação energética utilizados em centros de pesquisa por todo o mundo, inclusive no Brasil, como o ESP-r, ENERGYPLUS, TRNSYS e DOE. Este último passou a ser aplicado com maior frequência, desde os anos 1990, por grupos de pesquisadores brasileiros, principalmente em universidades da região Sul do país (MENDES; LAMBERTS; CUNHA NETO, 2001).

O programa DOE foi inicialmente desenvolvido por um consórcio de laboratórios americanos no final da década de 1970. Com o fim desse consórcio, o Departamento de Energia norteamericano assumiu o projeto e lançou o DOE-1, em 1978, a primeira versão do programa. Desde então, grupos de pesquisadores liderados pelo Lawrence Berkley National Laboratory passaram a ser responsáveis pelas revisões e atualizações do programa (PEDRINI, 1997).

Desde 1994, quando se encontrava na versão 2.1, o programa ganhou uma interface gráfica e passou a ser incluído em um novo pacote organizado pela Architectural Energy Corporation denominado VisualDOE, que lançou sua última versão (4.0) em 2004.

O VisualDOE 4.0 é um pacote que incorpora a versão DOE2.1E, incluindo ferramentas de análise de sistemas de iluminação e ventilação, aquecimento de água e envoltória da edificação. Além disso, realiza uma gama de simulações que incluem demandas de energia elétrica, consumo de gás e custos de implementação desses sistemas, com resultados horários sendo disponibilizados para facilitar as análises (VISUALDOE, 2004). 


\section{Programas de CFD}

O surgimento dos programas de CFD é atribuído à indústria aeroespacial nas décadas de 1960 e 1970. Hoje em dia são utilizados em diversas áreas, como as indústrias automobilística, naval e de manufaturados, astrofísica, meteorologia, oceanografia, etc. A engenharia e a arquitetura são campos mais recentes de aplicação dessas ferramentas, que tiveram sua evolução diretamente ligada ao desenvolvimento da informática (ANDERSON, 1995; BLAZEK, 2001).

As simulações em CFD voltadas para o ambiente construído podem ser divididas em estudos externos e internos. Nos estudos de fluxos internos, as maiores aplicações são voltadas para análises de qualidade do ar, ventilação artificial, sistemas de exaustão, riscos de incêndio, bem como predição da ventilação natural (GASPAR; BARROCA; PITARMA, 2003).

Os programas de CFD possuem interface gráfica que facilita a avaliação dos resultados e normalmente são estruturados em três módulos: o pré-processador, o módulo processador e o pósprocessador. No pré-processador o usuário pode definir as características geométricas do domínio, a malha com suas sub-regiões, as propriedades do fluido, as condições de contorno, etc. O módulo processador é responsável pelo cálculo do escoamento, que, na maioria dos pacotes, é feito pelo método dos elementos finitos. $\mathrm{O}$ pósprocessador oferece a visualização dos resultados do escoamento, com saídas gráficas e alfanuméricas (VERSTEEG; MALALASEKERA, 1995).

O PHOENICS é um programa de CFD para ambiente Windows. Sua interface valoriza principalmente a modelagem geométrica e a visualização dos resultados. Recomenda-se, no entanto, que o usuário tenha bom conhecimento de dinâmica dos fluidos e também de linguagem FORTRAN, para que todos os seus recursos sejam explorados e para que os resultados sejam confiáveis. O programa é um pacote de CFD para uso geral em diversas aplicações, que simula escoamentos de fluidos, reações químicas e físicas, além de tensões em sólidos imersos (LUDWIG, 2004). Como a maioria dos programas de CFD, trata as simulações em três fases, nas quais existem submódulos que trabalham de forma independente (Figura 1):

(a) o pré-processador possui dois módulos diferentes: o VR Editor, módulo de realidade virtual, e o Satellite, em modo de texto;

(b) o processador, que é constituído pelo módulo EARTH; e

(c) o pós-processador, que é composto de três módulos: o PHOTON, um programa de saída gráfica escrito em linguagem FORTRAN, o VR Viewer, que permite visualizar o escoamento, e o Autoplot, que produz saídas em forma de gráficos.

\section{Objetivo}

Este artigo tem como objetivo apresentar um conjunto de abordagens para a utilização de ferramentas de simulação computacional voltadas para o auxílio ao projeto quanto à previsão da ventilação natural e do desempenho térmico de edifícios do tipo galpão. Para isso, fez uso de um programa de CFD, o PHOENICS, e de outro de análise térmica e energética, o VisualDOE.



Fonte: adaptado de Spalding (2004).

Figura 1 - Esquema de utilização dos módulos disponíveis no PHOENICS 


\section{Método}

A metodologia parte de uma proposta de abordagens combinadas para avaliar o desempenho da ventilação natural e seu impacto no conforto térmico em determinado tipo de edificação. A proposta se inicia com a seleção de uma tipologia arquitetônica, que representa as edificações construídas com o sistema pré-moldado, caracterizando um caso-base. Após a simulação de seu desempenho, é possível criar uma variação que representa uma alternativa projetual simplificada, denominada de caso otimizado.

As simulações são divididas em duas abordagens distintas: de CFD e de desempenho térmico anual. A primeira, mais complexa, é o principal foco da pesquisa, pois está voltada para a avaliação do desempenho da ventilação natural para renovação do ar interno e definição dos campos de velocidade a partir de variações arquitetônicas. A segunda etapa é mais simplificada e visa identificar as temperaturas do ar interno na edificação. Mediante a combinação dos campos de velocidade e das taxas de renovação do ar com as temperaturas, é possível estimar o conforto térmico dos usuários.

A combinação das ferramentas tem dois propósitos. O primeiro é a identificação do impacto da geometria sobre a renovação de ar, calculada com base nas informações de vazão mássica extraídas do CFD (conforme em Determinação de taxas de renovação de ar), que, por sua vez, influencia as temperaturas do ar internas (desempenho térmico anual). $\mathrm{O}$ segundo propósito é a identificação dos benefícios da ventilação no aumento da temperatura-limite de conforto térmico, devido ao aumento da perda de calor por convecção superficial.

\section{Objeto de estudo}

A escolha dos edifícios do tipo galpão como objeto de estudo deveu-se a sua recorrente utilização na região de estudo, a cidade de Natal/RN (Figura 2). Esses edifícios possuem um sistema construtivo criado originalmente para uso industrial, mas que passou a ser adotado de forma crescente também pelos usos comercial e institucional. Sua larga utilização está associada a seu baixo custo, uma vez que é possível construir com maior rapidez e a menores preços, quando comparado ao sistema convencional de vigas e pilares moldados in loco.

Procurou-se delimitar um universo de estudo que contivesse exemplos representativos da tipologia dos galpões pré-moldados dentro do tecido urbano de Natal. A escolha do campus central da UFRN foi determinada pela presença de um número suficiente de amostras, além de se observar a predominância de uso da ventilação natural nesses edifícios.

\section{Definição das edificações típicas e do caso- base}

Como ponto de partida para a definição de um modelo típico dos edifícios construídos com estrutura pré-moldada, dentro do campus central da UFRN, realizou-se um levantamento de todas as edificações caracterizadas pelo emprego do sistema. A identificação dos casos foi facilitada pela predominante ausência de elementos arquitetônicos que disfarçassem o aspecto de galpão industrial característico à tipologia.

A etapa seguinte foi analisar as características construtivas de todos os edifícios para se chegar a um modelo típico. Por se tratar de um sistema modular, em que há uma repetição dos elementos arquitetônicos, foi possível estabelecer uma relação de variáveis a serem reproduzidas nas análises. Consideraram-se apenas as características mais importantes para as análises computacionais, eliminando-se aquelas que pudessem dificultar a modelagem dos casos. Foram dispensadas características como layout interno, tipologia e materiais das esquadrias, materiais de revestimento interno, entre outros. Dessa forma, foi possível reduzir o número de variáveis, que foram divididas em duas categorias, denominadas de qualitativas e quantitativas.

Para as características qualitativas foram destacados os seguintes elementos: (a) tipo de vedação: tijolos cerâmicos ou de
concreto, vazados ou maciços;

(b) revestimento externo: pintura, revestimento cerâmico ou texturizado na fachada;

(c) cor predominante do revestimento;

(d) tipo de telhas empregadas na cobertura;

(e) existência de forro e o material utilizado;

(f) tipos e disposição de aberturas nas fachadas longitudinais; e

(g) tipos de elementos vazados, quanto a sua geometria, de acordo com uma pré-seleção dos tipos encontrados no levantamento. 

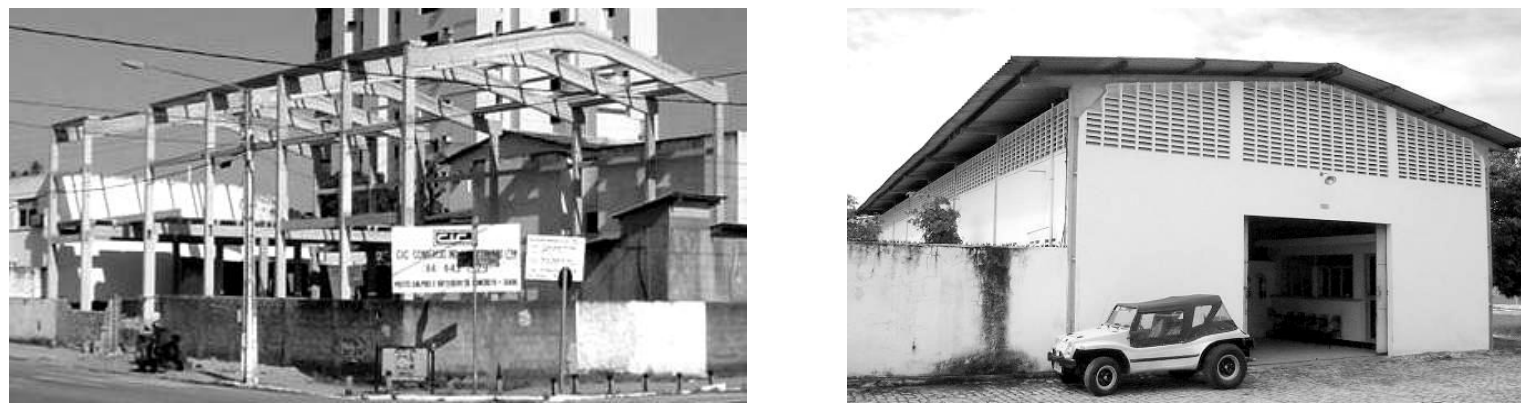

Figura 2 - Exemplos de galpões pré-fabricados encontrados na região de estudo

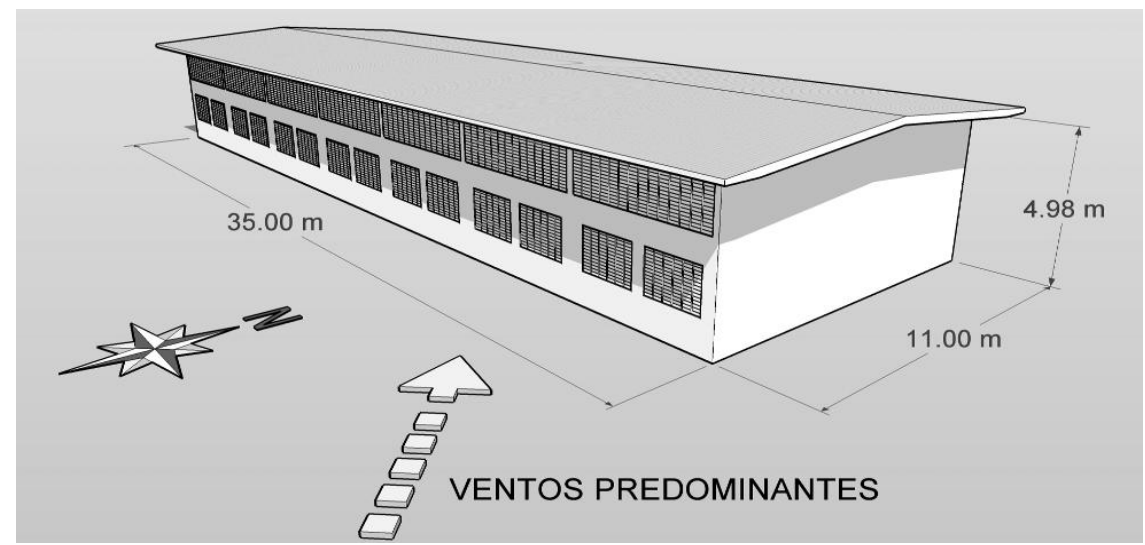

Figura 3 - Representação do modelo típico utilizado como caso-base nas simulações

Nas variáveis quantitativas foram considerados:

(a) orientação do eixo longitudinal do edifício;

(b) vão entre pilares;

(c) altura dos pilares;

(d) número de módulos que compõem o galpão;

(e) extensão dos beirais; e

(f) dimensões das aberturas.

Como a amostragem de edifícios foi pequena (20 no total) para se obter estatisticamente um modelo existente representativo de todos os demais, adotou-se uma simplificação de escolha baseada nas características mais frequentes encontradas nos levantamentos. Para as variáveis qualitativas adotou-se o parâmetro do modo, que aponta o valor mais repetido, que ocorre com maior frequência. Para as variáveis quantitativas, usou-se a mediana, ou seja, a medida central, que separa os valores inferiores dos superiores.

Essa simplificação garantiu a formulação de um modelo que, apesar de não existir no universo de pesquisa, reuniu as características mais comuns a todos eles. Esse modelo foi tomado como casobase para as simulações de CFD e de desempenho térmico (Figura 3).

\section{Caracterização das condições de contorno}

A condição de contorno procurou representar condições reais baseadas em dados de velocidade e de orientação do vento que ocorrem com maior frequência na área de estudo. Devido à indisponibilidade de dados coletados mais próximos da região estudada, foram usadas informações obtidas na estação climatológica do aeroporto internacional Augusto Severo, localizado na Grande Natal, distante aproximadamente $9 \mathrm{~km}$ do campus central da UFRN.

O período de medição compreendeu um total de 36 meses contínuos. Para identificar os valores de velocidade e direção dos ventos mais frequentes, utilizou-se a análise da rosa dos ventos, através do programa WRPLOT View 4.8.5. Optou-se por restringir os dados climáticos ao horário comercial, das 8 h00 às $18 \mathrm{~h} 00$. O número total de horas analisadas foi de 8.985. Após a tabulação dos dados, observou-se na rosa dos ventos (Figura 4) uma predominância da direção sudeste, compreendida entre os ângulos $120^{\circ}$ e $150^{\circ}$. A distribuição das velocidades em cada orientação foi uniforme.

No gráfico de distribuição das frequências (Figura 5), nota-se maior ocorrência das velocidades compreendidas entre $5 \mathrm{~m} / \mathrm{s}$ e $6 \mathrm{~m} / \mathrm{s}$ (15\%), similar à 
média geral de todas as velocidades ocorridas, que foi de $5,45 \mathrm{~m} / \mathrm{s}$.

Esses valores, no entanto, se referem a todos os ângulos de incidência encontrados, não estando associados a uma direção predominante. Constatou-se que os valores das velocidades e dos ângulos de incidência dos ventos mais frequentes não correspondem a um valor representativo da maioria das situações encontradas durante todo o período analisado. Se, por exemplo, fossem tomados os valores de $5,5 \mathrm{~m} / \mathrm{s}$ (equivalentes à média aritmética entre $5 \mathrm{~m} / \mathrm{s}$ e $6 \mathrm{~m} / \mathrm{s}$ ) e o ângulo de $120^{\circ}$ (de maior ocorrência), estar-se-ia adotando uma situação encontrada em apenas 2,9\% das horas, conforme a Tabela 1. Observa-se nela que as incidências predominantes (de $115^{\circ}$ a $155^{\circ}$ ) correspondem a $46,3 \%$ das horas analisadas (em destaque na última coluna da Tabela 1). Dentro dessas quatro faixas, as velocidades mais frequentes variam entre $5 \mathrm{~m} / \mathrm{s}$ e $8 \mathrm{~m} / \mathrm{s}$, correspondentes a $41,8 \%$ das horas (linha inferior da tabela). Entretanto, o número de horas em que essas variáveis ocorrem em conjunto equivale a 23,6\% (em destaque no centro da tabela).

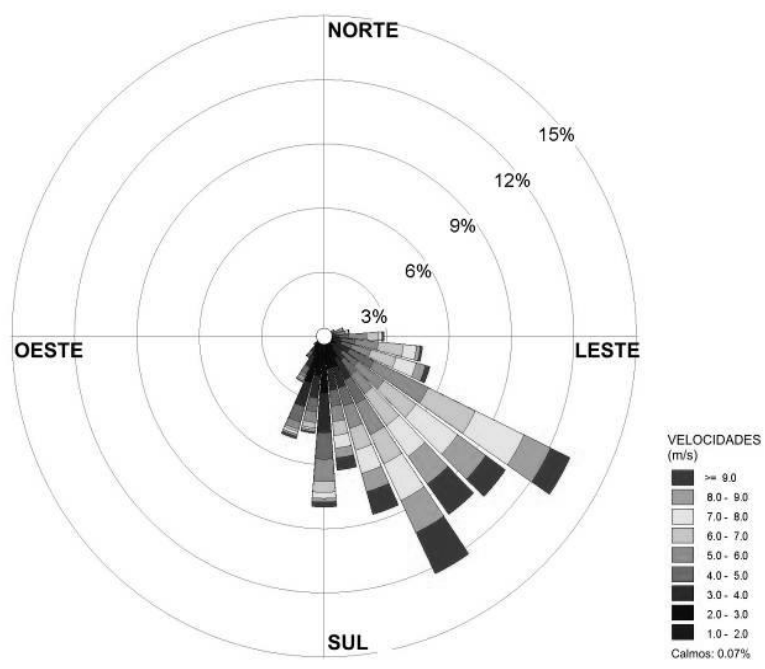

Figura 4 - Rosa dos ventos para o horário comercial no período analisado



Figura 5 - Frequências de velocidades ocorridas no período analisado 


\begin{tabular}{|c|c|c|c|c|c|c|c|c|c|c|}
\hline Vel. / Ang. & $1.0-2.0$ & $2.0-3.0$ & $3.0-4.0$ & $4.0-5.0$ & $5.0-6.0$ & $6.0-7.0$ & $7.0-8.0$ & $8.0-9.0$ & $>=9.0$ & Total \\
\hline 355 a 5 & $0.03 \%$ & $0.00 \%$ & $0.00 \%$ & $0.00 \%$ & $0.00 \%$ & $0.00 \%$ & $0.00 \%$ & $0.00 \%$ & $0.00 \%$ & $0.03 \%$ \\
\hline 5 a 15 & $0.00 \%$ & $0.00 \%$ & $0.00 \%$ & $0.01 \%$ & $0.02 \%$ & $0.00 \%$ & $0.00 \%$ & $0.00 \%$ & $0.00 \%$ & $0.03 \%$ \\
\hline 15 a 25 & $0.02 \%$ & $0.00 \%$ & $0.01 \%$ & $0.00 \%$ & $0.00 \%$ & $0.00 \%$ & $0.00 \%$ & $0.00 \%$ & $0.00 \%$ & $0.03 \%$ \\
\hline 25 a 35 & $0.03 \%$ & $0.03 \%$ & $0.00 \%$ & $0.01 \%$ & $0.00 \%$ & $0.02 \%$ & $0.00 \%$ & $0.00 \%$ & $0.01 \%$ & $0.11 \%$ \\
\hline 35 a 45 & $0.03 \%$ & $0.02 \%$ & $0.02 \%$ & $0.01 \%$ & $0.02 \%$ & $0.00 \%$ & $0.01 \%$ & $0.00 \%$ & $0.00 \%$ & $0.12 \%$ \\
\hline 45 a 55 & $0.01 \%$ & $0.03 \%$ & $0.01 \%$ & $0.03 \%$ & $0.03 \%$ & $0.03 \%$ & $0.00 \%$ & $0.00 \%$ & $0.01 \%$ & $0.17 \%$ \\
\hline 55 a 65 & $0.01 \%$ & $0.09 \%$ & $0.11 \%$ & $0.11 \%$ & $0.11 \%$ & $0.10 \%$ & $0.01 \%$ & $0.00 \%$ & $0.01 \%$ & $0.56 \%$ \\
\hline 65 a 75 & $0.01 \%$ & $0.16 \%$ & $0.12 \%$ & $0.19 \%$ & $0.30 \%$ & $0.13 \%$ & $0.03 \%$ & $0.01 \%$ & $0.00 \%$ & $0.96 \%$ \\
\hline 75 a 85 & $0.04 \%$ & $0.12 \%$ & $0.21 \%$ & $0.23 \%$ & $0.38 \%$ & $0.18 \%$ & $0.03 \%$ & $0.00 \%$ & $0.01 \%$ & $1.21 \%$ \\
\hline 85 a 95 & $0.13 \%$ & $0.18 \%$ & $0.39 \%$ & $0.47 \%$ & $0.88 \%$ & $0.57 \%$ & $0.16 \%$ & $0.03 \%$ & $0.07 \%$ & $2.87 \%$ \\
\hline 95 a 105 & $0.06 \%$ & $0.29 \%$ & $0.47 \%$ & $0.69 \%$ & $1.11 \%$ & $1.21 \%$ & $0.62 \%$ & $0.18 \%$ & $0.11 \%$ & $4.74 \%$ \\
\hline 105 a 115 & $0.08 \%$ & $0.31 \%$ & $0.47 \%$ & $0.52 \%$ & $0.95 \%$ & $1.26 \%$ & $1.00 \%$ & $0.47 \%$ & $0.21 \%$ & $5.26 \%$ \\
\hline 115 a 125 & $0.19 \%$ & $0.40 \%$ & $0.75 \%$ & $1.29 \%$ & $2.90 \%$ & $2.50 \%$ & $2.60 \%$ & $1.40 \%$ & $1.04 \%$ & $13.08 \%$ \\
\hline 125 a 135 & $0.08 \%$ & $0.39 \%$ & $0.61 \%$ & $0.90 \%$ & $1.55 \%$ & $1.89 \%$ & $2.45 \%$ & $1.67 \%$ & $1.16 \%$ & $10.70 \%$ \\
\hline 135 a 145 & $0.14 \%$ & $0.49 \%$ & $0.72 \%$ & $0.83 \%$ & $1.10 \%$ & $1.84 \%$ & $1.77 \%$ & $1.58 \%$ & $1.75 \%$ & $10.23 \%$ \\
\hline 145 a 155 & $0.14 \%$ & $0.96 \%$ & $1.15 \%$ & $1.24 \%$ & $1.61 \%$ & $1.50 \%$ & $1.90 \%$ & $1.66 \%$ & $2.13 \%$ & $12.29 \%$ \\
\hline 155 a 165 & $0.28 \%$ & $1.22 \%$ & $0.99 \%$ & $0.88 \%$ & $1.09 \%$ & $1.07 \%$ & $1.11 \%$ & $0.89 \%$ & $1.10 \%$ & $8.64 \%$ \\
\hline 165 a 175 & $0.37 \%$ & $1.15 \%$ & $1.01 \%$ & $0.75 \%$ & $0.73 \%$ & $0.65 \%$ & $0.60 \%$ & $0.46 \%$ & $0.57 \%$ & $6.28 \%$ \\
\hline 175 a 185 & $0.72 \%$ & $1.91 \%$ & $1.86 \%$ & $1.24 \%$ & $1.05 \%$ & $0.50 \%$ & $0.29 \%$ & $0.17 \%$ & $0.22 \%$ & $7.96 \%$ \\
\hline 185 a 195 & $0.48 \%$ & $1.37 \%$ & $1.05 \%$ & $0.65 \%$ & $0.51 \%$ & $0.26 \%$ & $0.09 \%$ & $0.09 \%$ & $0.07 \%$ & $4.55 \%$ \\
\hline 195 a 205 & $0.72 \%$ & $1.54 \%$ & $1.16 \%$ & $0.73 \%$ & $0.36 \%$ & $0.11 \%$ & $0.13 \%$ & $0.10 \%$ & $0.11 \%$ & $4.96 \%$ \\
\hline 205 a 215 & $0.28 \%$ & $0.75 \%$ & $0.57 \%$ & $0.36 \%$ & $0.16 \%$ & $0.08 \%$ & $0.07 \%$ & $0.09 \%$ & $0.03 \%$ & $2.37 \%$ \\
\hline 215 a 225 & $0.24 \%$ & $0.45 \%$ & $0.22 \%$ & $0.20 \%$ & $0.07 \%$ & $0.02 \%$ & $0.00 \%$ & $0.03 \%$ & $0.00 \%$ & $1.24 \%$ \\
\hline 225 a 235 & $0.11 \%$ & $0.23 \%$ & $0.16 \%$ & $0.06 \%$ & $0.03 \%$ & $0.00 \%$ & $0.00 \%$ & $0.01 \%$ & $0.00 \%$ & $0.60 \%$ \\
\hline 235 a 245 & $0.11 \%$ & $0.07 \%$ & $0.11 \%$ & $0.08 \%$ & $0.01 \%$ & $0.00 \%$ & $0.00 \%$ & $0.00 \%$ & $0.00 \%$ & $0.38 \%$ \\
\hline 245 a 255 & $0.08 \%$ & $0.03 \%$ & $0.00 \%$ & $0.00 \%$ & $0.00 \%$ & $0.01 \%$ & $0.00 \%$ & $0.00 \%$ & $0.00 \%$ & $0.12 \%$ \\
\hline 255 a 265 & $0.03 \%$ & $0.02 \%$ & $0.01 \%$ & $0.00 \%$ & $0.00 \%$ & $0.00 \%$ & $0.00 \%$ & $0.00 \%$ & $0.00 \%$ & $0.07 \%$ \\
\hline 265 a 275 & $0.03 \%$ & $0.02 \%$ & $0.00 \%$ & $0.00 \%$ & $0.00 \%$ & $0.00 \%$ & $0.00 \%$ & $0.00 \%$ & $0.00 \%$ & $0.06 \%$ \\
\hline 275 a 285 & $0.02 \%$ & $0.01 \%$ & $0.01 \%$ & $0.01 \%$ & $0.00 \%$ & $0.00 \%$ & $0.00 \%$ & $0.00 \%$ & $0.00 \%$ & $0.06 \%$ \\
\hline 285 a 295 & $0.01 \%$ & $0.00 \%$ & $0.00 \%$ & $0.00 \%$ & $0.00 \%$ & $0.00 \%$ & $0.00 \%$ & $0.00 \%$ & $0.00 \%$ & $0.01 \%$ \\
\hline 295 a 305 & $0.08 \%$ & $0.02 \%$ & $0.00 \%$ & $0.00 \%$ & $0.00 \%$ & $0.01 \%$ & $0.01 \%$ & $0.00 \%$ & $0.00 \%$ & $0.12 \%$ \\
\hline 305 a 315 & $0.01 \%$ & $0.01 \%$ & $0.00 \%$ & $0.00 \%$ & $0.00 \%$ & $0.00 \%$ & $0.00 \%$ & $0.00 \%$ & $0.00 \%$ & $0.02 \%$ \\
\hline 315 a 325 & $0.00 \%$ & $0.00 \%$ & $0.01 \%$ & $0.00 \%$ & $0.00 \%$ & $0.00 \%$ & $0.00 \%$ & $0.00 \%$ & $0.00 \%$ & $0.01 \%$ \\
\hline 325 a 335 & $0.02 \%$ & $0.00 \%$ & $0.01 \%$ & $0.00 \%$ & $0.01 \%$ & $0.00 \%$ & $0.00 \%$ & $0.00 \%$ & $0.00 \%$ & $0.04 \%$ \\
\hline 335 a 345 & $0.00 \%$ & $0.01 \%$ & $0.00 \%$ & $0.00 \%$ & $0.00 \%$ & $0.00 \%$ & $0.00 \%$ & $0.00 \%$ & $0.00 \%$ & $0.01 \%$ \\
\hline 345 a 355 & $0.00 \%$ & $0.01 \%$ & $0.01 \%$ & $0.01 \%$ & $0.01 \%$ & $0.00 \%$ & $0.00 \%$ & $0.00 \%$ & $0.00 \%$ & $0.04 \%$ \\
\hline Total & $4.63 \%$ & $12.30 \%$ & $12.22 \%$ & $11.50 \%$ & $15.00 \%$ & $13.95 \%$ & $12.90 \%$ & $8.84 \%$ & $8.60 \%$ & \\
\hline
\end{tabular}

Fonte: adaptado de WRPLOT View (2004).

Tabela 1 - Frequência percentual das direções e velocidades entre 2002 e 2005

A partir dessa análise, adotou-se o critério de médias ponderadas dos valores de velocidade e ângulos, destacados na tabela, para se extraírem valores que representassem a maior probabilidade de ocorrência das variáveis em conjunto. Ficou estabelecido que a ventilação considerada predominante é caracterizada por ventos com velocidade média de $6,6 \mathrm{~m} / \mathrm{s}$ e incidência média de $133^{\circ}$ sudeste. Essa velocidade foi corrigida para as alturas apropriadas do estudo, por meio de equação elaborada pela ASHRAE (HEIJMANS, 2002), considerando as características da ocupação do solo como área suburbana.

\section{Arquivo climático para simulação térmica e energética}

O arquivo climático escolhido para a simulação térmica é do tipo TRY. O arquivo corresponde ao ano de 1954, obtido por Goulart (1993). O arquivo climático foi a versão 2006,
"NatalTRY1954_06.bin", disponibilizado no website do LabEEE ${ }^{1}$. O gráfico da Figura 6 mostra as curvas de temperatura de bulbo seco e a radiação solar obtidas pelo TRY de 1954.

\section{Definição do índice de conforto térmico}

A determinação da temperatura-limite de conforto é polêmica, especialmente para regiões de clima quente e úmido, que empregam condicionamento passivo. Para esta pesquisa, foram considerados os critérios de escolha adotados por Oliveira (2006), que fez opção pelo modelo adaptativo de Humphreys (1978 apud NICOL, 2004). Entre diversos modelos analisados pelo autor, a escolha teve como critérios o próprio clima e estudos de conforto térmico realizados por Araújo (2001) para o clima de Natal, RN.

\footnotetext{
${ }^{1}$ Laboratório de Eficiência Energética em Edificações da Universidade Federal de Santa Catarina.
} 


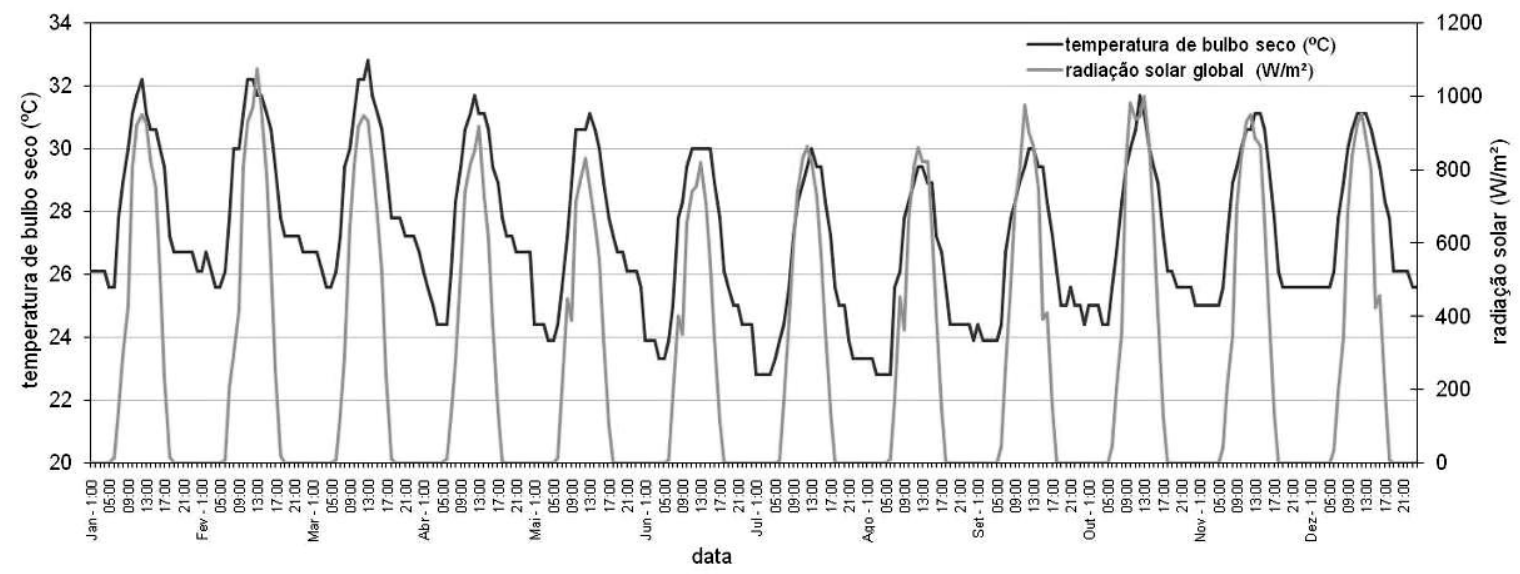

Figura 6 - Temperatura de bulbo seco e radiação solar de Natal segundo TRY de 1954

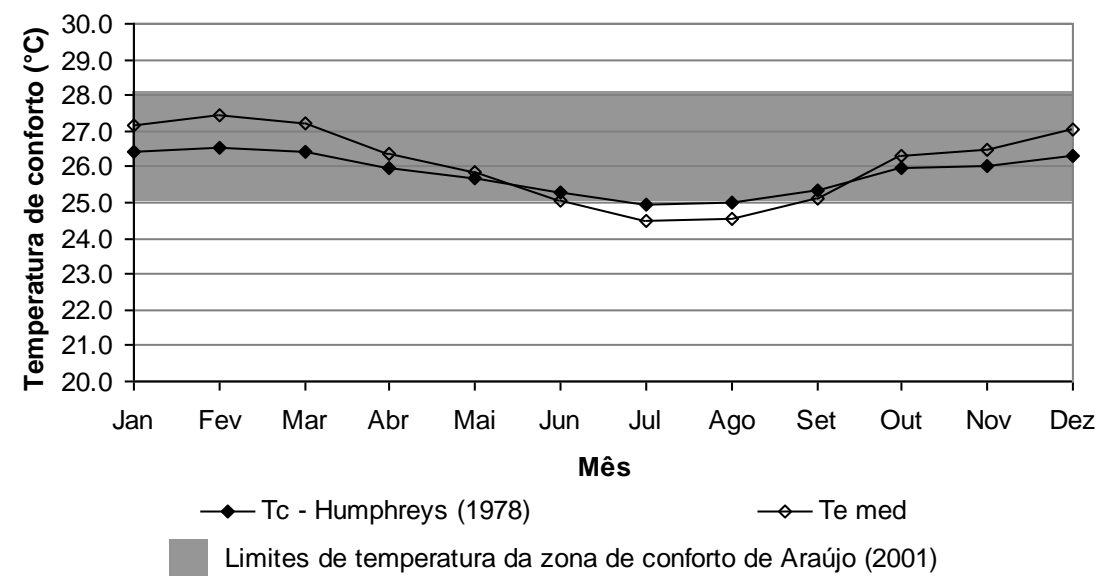

Fonte: Oliveira (2006).

Figura 7 - Temperaturas corrigidas com o modelo adaptativo de Humphreys para o clima de Natal (TRY de 1954) e os limites de temperatura da zona de conforto de Araújo (2001)

O primeiro critério parte da importância em considerar a adaptabilidade dos ocupantes de edificações ventiladas naturalmente (NICOL; PARSONS, 2002). O segundo critério baseia-se em Araújo (2001), que determinou uma zona de conforto térmico para o clima de Natal com limites de temperatura de bulbo seco entre $25,1^{\circ} \mathrm{C}$ e 28,1 ${ }^{\circ} \mathrm{C}$, e de $69 \%$ e $92 \%$ para umidade relativa.

Os resultados encontrados para condições de temperatura do ar obtidos através do modelo de Humphreys de 1978 estão praticamente dentro da faixa de conforto de Araújo (2001), conforme gráfico da Figura 7 (OLIVEIRA, 2006).

Ao se adotar o modelo de Humphreys (1978), considerando valores médios anuais, identificou-se o limite da temperatura de conforto, sem ventilação em $28{ }^{\circ} \mathrm{C}, 31^{\circ} \mathrm{C}$ para velocidade do ar de $0,5 \mathrm{~m} / \mathrm{s}$; $32{ }^{\circ} \mathrm{C}$ para velocidade de até $1,0 \mathrm{~m} / \mathrm{s}$; e $33^{\circ} \mathrm{C}$ para velocidade de $2,0 \mathrm{~m} / \mathrm{s}$. Esses valores foram utilizados para a análise das temperaturas ocorridas dentro do galpão, identificando a quantidade de horas em que ocorre conforto térmico e aquelas em que há necessidade de ventilação natural.

\section{Análises preliminares}

\section{Simulações da ventilação}

A modelagem dos casos em CFD considerou primeiramente a definição das dimensões do domínio e da malha. Inicialmente, optou-se pelo modelo mais próximo da realidade, onde o galpão está localizado no centro do domínio (Figura 8) para reproduzir os escoamentos de ar externo e interno. 
A simulação desse modelo demandou o refinamento localizado da malha para que as menores geometrias fossem capturadas na simulação, juntamente com todo o galpão. A versão do programa PHOENICS (3.6.0) utilizada na pesquisa apresentou sucessivas falhas no recurso de refino denominado fine grid objects, fazendo com que esda estratégia fosse abandonada para as simulações seguintes.

A partir daí, passou-se a estudar as possibilidades oferecidas pelo programa para viabilizar as simulações diante das limitações apresentadas. Visualizou-se um cenário que apontou para duas alternativas, discutidas a seguir.

\section{Modelagem em domínio único}

A primeira alternativa foi trabalhar com um domínio único representando os limites internos do galpão, onde cada abertura de entrada é caracterizada por um inlet, e as saídas, por outlets. A cobertura do galpão é representada por um sólido. Nesse modelo, a malha pôde ser dimensionada com células de $15 \mathrm{~cm}$ x $15 \mathrm{~cm}$ x 15 $\mathrm{cm}$ em todo o domínio, permitindo um equilíbrio entre tempo de processamento e detalhamento do escoamento (Figura 9).

A caracterização das condições de contorno foi simplificada. As velocidades de entrada foram corrigidas para a altura do centro geométrico de cada inlet. Como as aberturas do galpão típico são vedadas com elementos vazados do tipo venezianas, foi preciso simular a influência de suas geometrias no escoamento. Para isso, empregou-se o método de decomposição dos vetores da velocidade, para se acharem os valores das velocidades em X, Y e Z (Figura 10).

A decomposição dos vetores se mostrou eficaz na medida em que simplifica a modelagem dos casos. Porém, o método não considera efeitos como perdas de carga na entrada e saída do escoamento, além dos diferentes coeficientes de pressão ocorridos na fachada, devido à geometria externa da edificação. A tentativa de reduzir essas incertezas levou à formulação de uma nova abordagem, como mostrado a seguir.

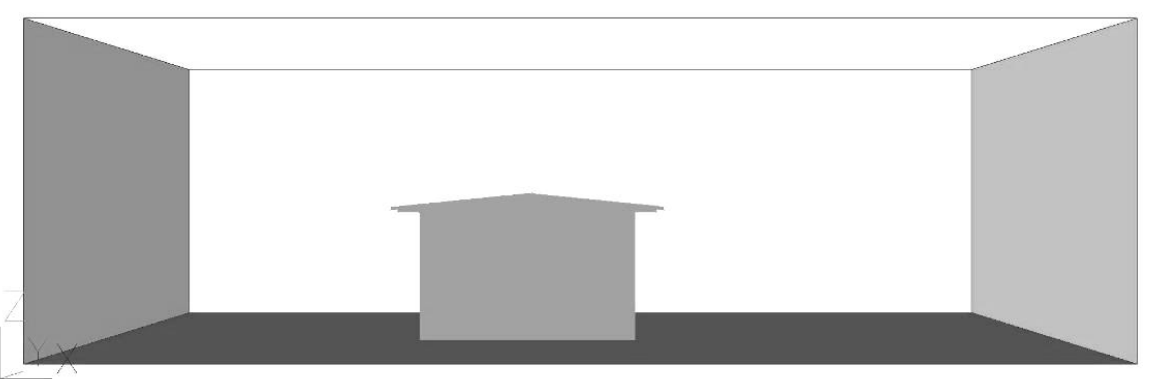

Figura 8 - Domínio construído com modelo posicionado no centro

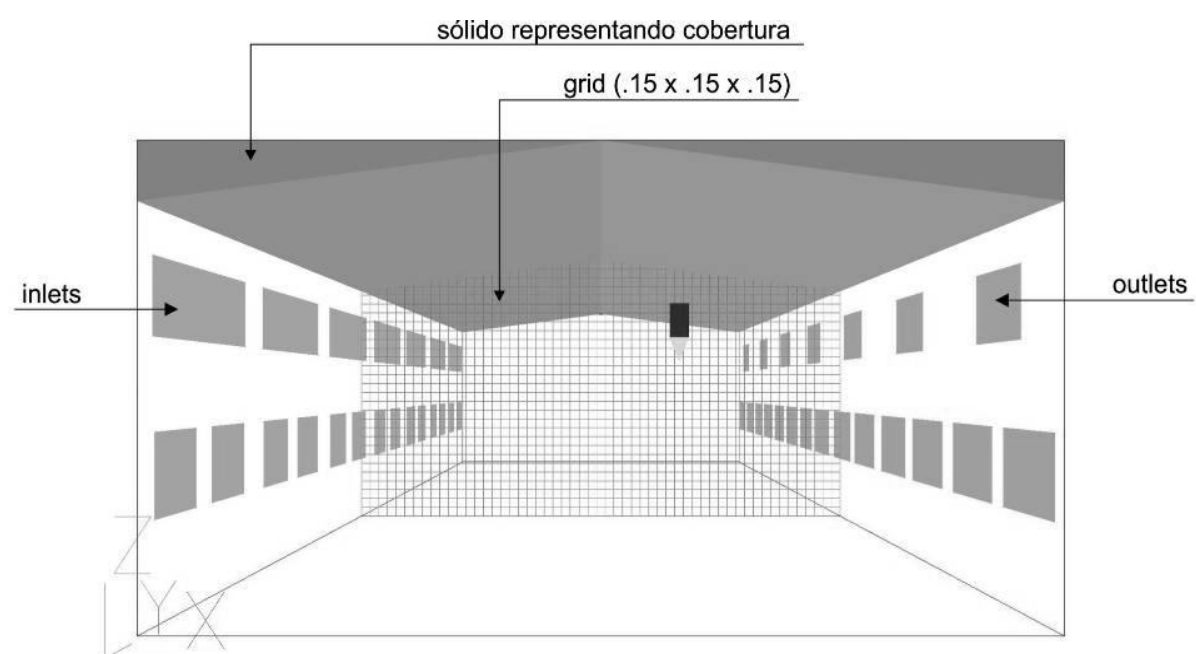

Figura 9 - Domínio representando geometria interna do galpão típico 

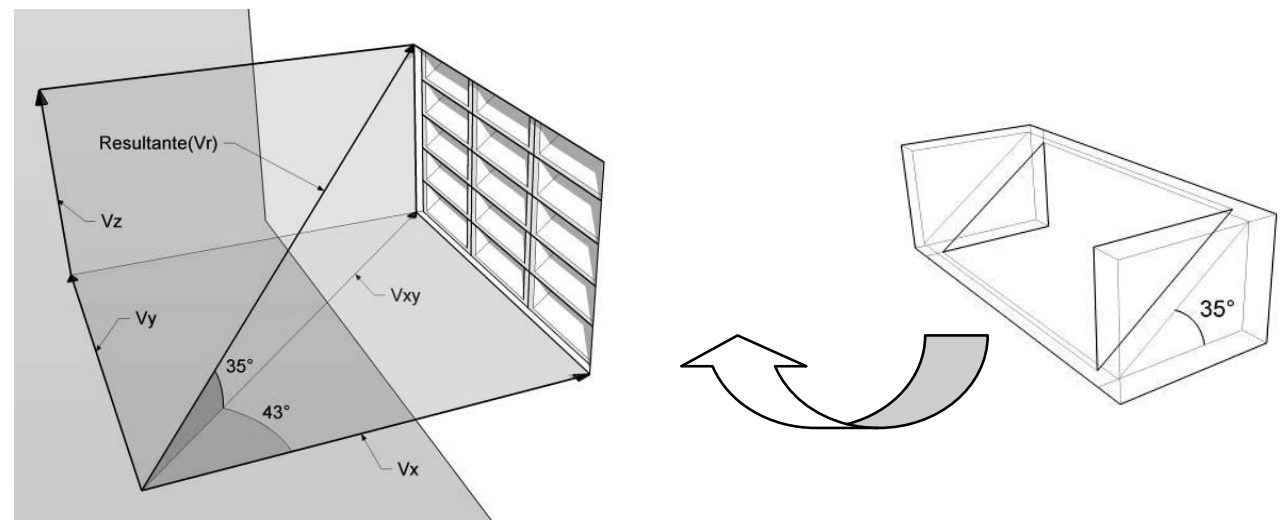

Figura 10 - Esquema de decomposição de vetores no cálculo das velocidades em X, Y e Z


Figura 11 - Domínio representando trecho da fachada do galpão típico com inlets, outlets e regiões de refino na geometria dos elementos vazados

\section{Modelagem em domínios separados}

A segunda abordagem é uma evolução da anterior e tem como objetivo aumentar a fidelidade das simulações. Propôs-se a divisão das simulações em duas etapas, através de dois modelos diferentes. $\mathrm{O}$ primeiro tem domínio e malha dimensionados para a análise isolada do escoamento nos cobogós. Foi construído um domínio representando um trecho da fachada do galpão típico com a geometria das aberturas compostas de elementos vazados e parte da cobertura interna (Figura 11).

Com os campos de velocidade conhecidos, as velocidades na saída dos elementos vazados serviram como variáveis de entrada no caso seguinte. As velocidades do elemento central de cada abertura foram transferidas para o domínio do caso do galpão típico, informadas em cada objeto do tipo inlet.
Essa abordagem foi considerada mais viável, pois ofereceu a melhor relação entre vantagens e restrições das alternativas, considerando o detalhamento do modelo e a capacidade de processamento do equipamento disponível.

\section{Determinação de taxas de renovação de ar}

A renovação de ar ocorrida dentro do domínio pode ser quantificada a partir da leitura, no programa, da quantidade de massa que entra e sai do domínio, por suas aberturas (inlets e outlets). Como a vazão mássica é dada em quilogramas por segundo, foi necessário convertê-la para vazão volumétrica. Para isso, adotou-se a temperatura de referência de $30^{\circ} \mathrm{C}$, pressão atmosférica no nível do mar e densidade do ar de $1,165 \mathrm{~kg} / \mathrm{m}^{3}$ (KREITH, 2000). No caso do galpão típico, temse: 
(a) para determinar a vazão do galpão típico em $\mathrm{m}^{3} / \mathrm{h}(\mathrm{Q})$, utiliza-se a Equação 1:

$\mathrm{Q}=\mathrm{Q}_{1} / \rho$,

Eq. 1

Onde:

$\mathrm{Q}_{1}=338.724 \mathrm{~kg} / \mathrm{h}$ (vazão mássica $\left(\mathrm{Q}_{\mathrm{r}}\right)$ convertida para $\mathrm{kg} / \mathrm{h})$;

$\rho=1,165 \mathrm{~kg} / \mathrm{m}^{3}$ (densidade do ar para a temperatura adotada); e

$\mathrm{Q}=\mathrm{Q}_{1} / \rho=290.750,21 \mathrm{~m}^{3} / \mathrm{h}$.

(b) para o cálculo do número de renovações adota-se a Equação 2:

$\mathrm{R}=\mathrm{Q} / \mathrm{V}$,

Eq. 2

Onde:

$\mathrm{Q}=290.750,21 \mathrm{~m}^{3} / \mathrm{h}$

$\mathrm{V}=1.982,75 \mathrm{~m}^{3}$ (volume do galpão típico); e

$\mathrm{R}=\mathrm{Q} / \mathrm{V}=146,63$ renovações/hora.

Dessa forma, tem-se um número de aproximadamente 147 renovações de ar em uma hora dentro do galpão típico (caso-base). Esse valor foi adotado como parâmetro para as análises de desempenho térmico do galpão para as simulações térmicas no VisualDOE, permitindo correlacioná-lo com as temperaturas internas e as faixas de conforto consideradas no estudo.

\section{Determinação de campos de velocidade}

O módulo de visualização do PHOENICS, o $V R$ Viewer, permite identificar os campos de velocidade dentro do domínio, a partir da localização da sonda de medição (probe). Do ponto em que está a sonda são gerados planos nos eixos $\mathrm{X}, \mathrm{Y}$ e $\mathrm{Z}$, que fornecem três formas diferentes de visualização: vetores, contornos e superfícies (Figura 12).

Para as simulações geradas nesta pesquisa, foram utilizados os três módulos de visualização, uma vez que eles se complementam. No entanto, as três modalidades de visualização não disponibilizam um dado importante para a avaliação dos campos de velocidade, que é a porcentagem que cada velocidade ocorre dentro do domínio. Nesse caso, a avaliação tem que ser puramente visual.

Para a determinação de valores de velocidades em determinada área dentro do domínio, o contorno se mostra eficiente por permitir ajustar os limites do plano a qualquer dimensão. Esse recurso foi utilizado para a leitura das velocidades de saída nas aberturas do domínio reduzido, permitindo achar as velocidades $\mathrm{Vx}, \mathrm{Vy}$ e $\mathrm{Vz}$, declarando-as como velocidades de entrada nos inlets do domínio do galpão.

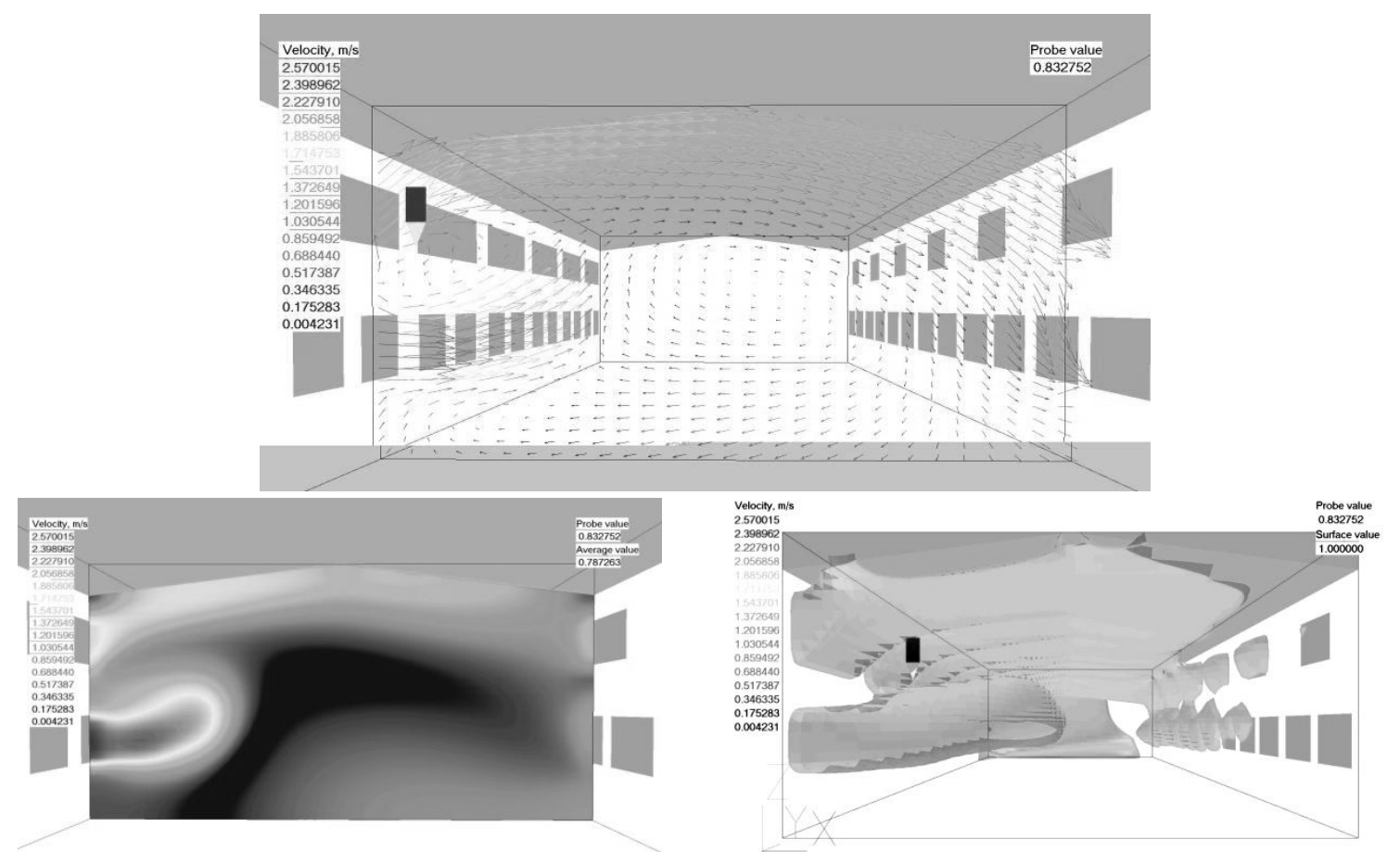

Figura 12 - Formas de visualização dos campos de velocidade no programa PHOENICS (respectivamente vetores, contornos e superfícies) 


\section{Simulações térmicas}

Como a ênfase da pesquisa está no uso da simulação em CFD, essa abordagem tem um caráter complementar, que é a geração de temperaturas internas de acordo com alternativas de envoltórias. A simulação térmica foi realizada no programa VisualDOE.

Em geral, os programas de simulação energética são muito limitados para calcular a ventilação natural, como foi discutido por Oliveira (2006). Por isso, optou-se por analisar o desempenho da edificação de acordo com taxas de renovação de ar predefinidas.

As simulações empregaram um ano climático de referência do tipo TRY de 1954. Apenas as horas simuladas no horário comercial que coincidem com a faixa de velocidade e orientação do vento, consideradas típicas, foram selecionados para a análise, resultando em apenas 244 horas ou 5,6\% do período de uso da edificação.

\section{Modelagem dos casos}

O modelo reproduz um galpão com alvenaria convencional de tijolos de oito furos $(\mathrm{U}=2,1$ $\mathrm{W} / \mathrm{m}^{2} \mathrm{~K}$ e $\alpha$ de $70 \%$ ), cobertura de fibrocimento (U $=5,5 \mathrm{~W} / \mathrm{m}^{2} \mathrm{~K}$ e $\alpha=70 \%$ ), com aberturas sombreadas por cobogós, com densidade de iluminação artificial de $6 \mathrm{~W} / \mathrm{m}^{2}$, densidade de equipamentos de $3 \mathrm{~W} / \mathrm{m}^{2}$, ocupação de 29 pessoas, que é usado entre as $8 \mathrm{~h} 00$ e as 18h00. As temperaturas horárias são obtidas simulando-se um sistema de ar condicionado com capacidade de resfriamento nulo.

Foram consideradas duas alternativas para analisar o desempenho térmico: modelagem de uma única zona e de duas zonas. Ambas apresentam aproximações que podem comprometer a fidelidade dos resultados. Na modelagem de uma única zona, a aproximação mais questionável é a

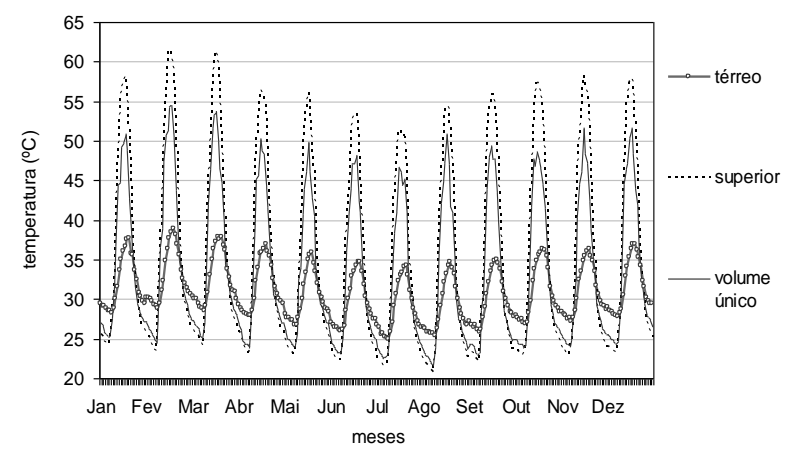

formação de gradientes de temperatura verticais, que são ignorados pelo VisualDOE, porque este considera a temperatura da zona uniforme. Operacionalmente, as aberturas das fachadas foram simplificadas para considerar aberturas em alturas diferentes em cada módulo, onde foram inseridas de forma customizada (uma a uma, através das coordenadas $\mathrm{X}$ e $\mathrm{Y}$ ). $\mathrm{Na}$ modelagem de duas zonas, uma sobre a outra, as temperaturas são calculadas separadamente, pois o programa considera que há uma alta transmitância térmica entre elas, de aproximadamente $14,8 \mathrm{~W} / \mathrm{m}^{2} \mathrm{~K}$.

A comparação das simulações para 10 trocas de ar mostrou que as temperaturas do modelo de uma única zona são intermediárias em relação às temperaturas das duas zonas do outro modelo. Entretanto, as temperaturas do térreo foram baixas demais, se comparadas com a percepção de conforto térmico que se tem ao visitar os galpões, provavelmente devido à irradiação de calor das superfícies. A comparação das temperaturas radiantes médias para as três zonas demonstra que o ambiente térreo é pouco influenciado (Figura 13). Ainda que o programa considere uma baixa resistência térmica entre a zona térrea e a superior, a troca de calor por radiação térmica é subestimada.

Nas duas modelagens, há considerações grosseiras em relação à formação de gradientes de temperatura e em relação à radiação térmica. Como as análises com maiores taxas de renovação de ar tendem a minimizar os gradientes de temperatura, optou-se em contornar as limitações da radiação térmica com a inserção de um forro simples. Assim, as temperaturas se tornaram mais próximas e mais convincentes (Figura 14). Como o desempenho da zona térrea ainda apresenta baixas temperaturas radiantes médias, incompatíveis com a realidade, optou-se pela análise das temperaturas a partir do modelo com uma única zona, porém com forro.



Figura 13 - Temperaturas médias e temperaturas radiantes médias mensais dos modelos analisados 

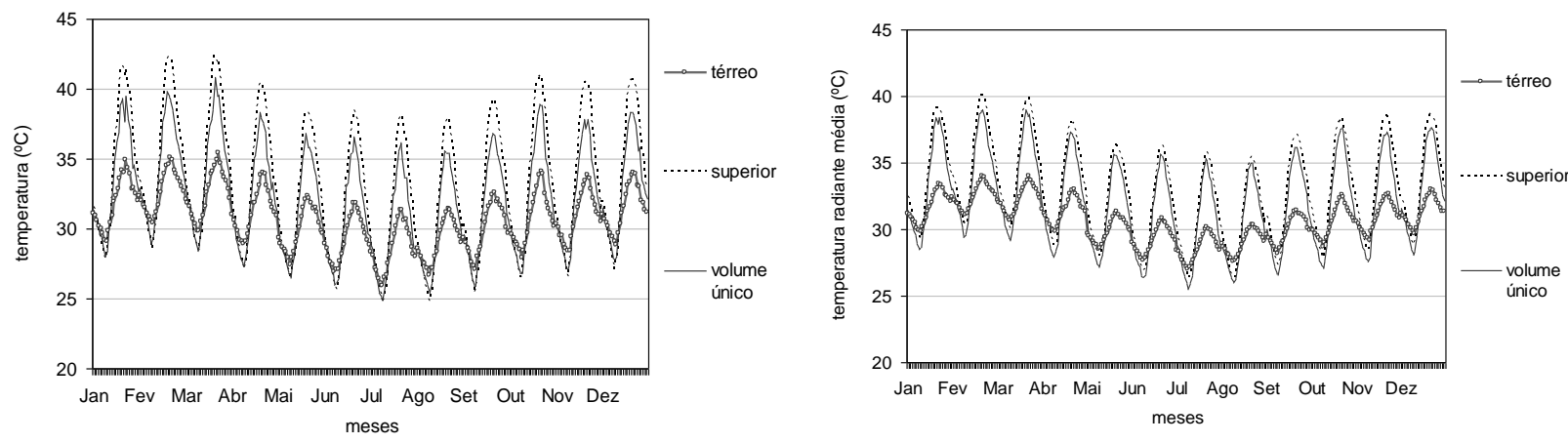

Figura 14 - Temperaturas médias mensais e temperaturas radiantes médias mensais dos modelos com forro
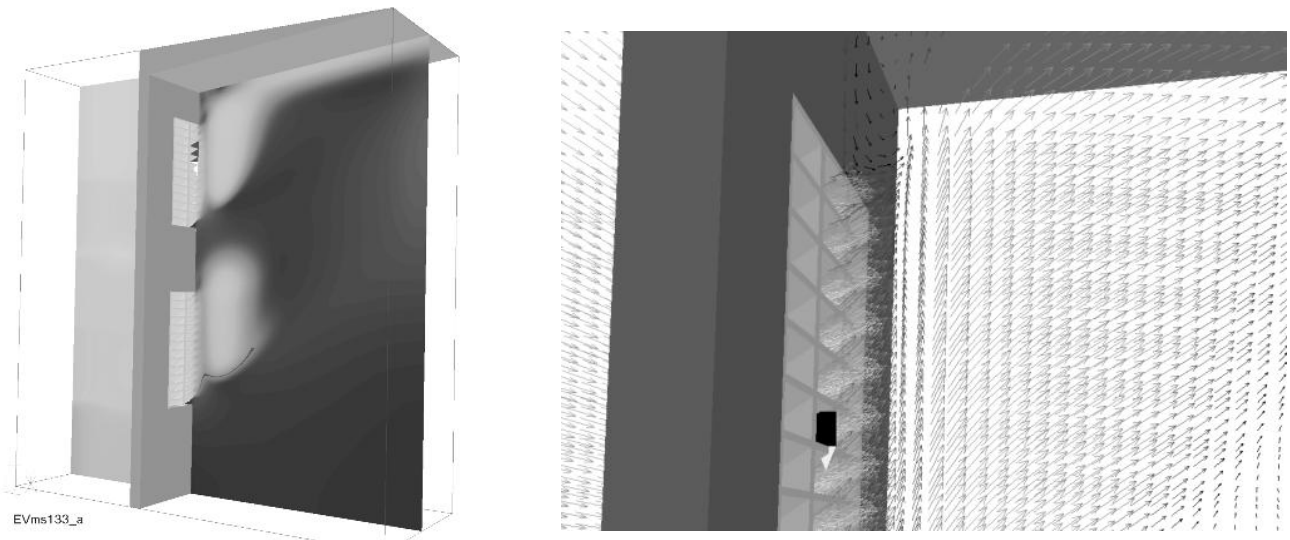

Figura 15 - Visualização dos campos de velocidade do ar em trecho da fachada do galpão típico através de contornos e de vetores

\section{Resultados}

\section{Simulações da ventilação}

Como foi descrito, as simulações em CFD foram divididas em duas etapas, correspondentes às escalas dos domínios estudados. As simulações do domínio reduzido geraram condições de contorno para as simulações do domínio que representa o interior do galpão. $O$ caso-base foi simulado na primeira etapa para identificar a distribuição do escoamento e os campos de velocidade.

\section{Caso-base}

$\mathrm{O}$ caso-base foi simulado inicialmente com o domínio que reproduz apenas um trecho da fachada do galpão, com as aberturas compostas de elementos vazados. Os resultados mostraram o desvio no escoamento provocado pelos cobogós, que tendem a direcionar o ar para cima da área ocupada pelos usuários (Figura 15).

$\mathrm{Na}$ simulação do interior do galpão, a direção do fluxo e os campos de velocidade do ar foram visualizados, notando-se claramente as maiores velocidades do ar sendo desviadas para o alto, deixando a área de ocupação pelo usuário (estipulada em $1,20 \mathrm{~m}$ ) praticamente sem ventilação, com valores próximos de $0,2 \mathrm{~m} / \mathrm{s}$ no ponto de localização da sonda (Figura 16).

Esse desempenho da ventilação levou às primeiras considerações sobre a aplicação do elemento vazado do tipo veneziana. Para aberturas posicionadas ao nível do usuário, o elemento mostrou-se inadequado por desviar o fluxo de ar para cima da área potencialmente ocupada. Nas aberturas superiores, o emprego desse cobogó pode contribuir para a redução da temperatura e da irradiação de calor da cobertura. A vazão mássica resultante dessa geometria foi de $94,09 \mathrm{~kg} / \mathrm{s}$, que equivale a 147 renovações por hora.

\section{Caso otimizado}

O caso denominado otimizado compreende duas alterações da geometria: a substituição dos elementos vazados inferiores por aberturas livres, preservando-os nas aberturas superiores; e o 
aumento das dimensões das aberturas inferiores (Figura 17).

Nas primeiras visualizações, ainda no domínio menor, foi possível comparar a diferença nos escoamentos inferior e superior. Enquanto a abertura livre praticamente não influencia a direção do vento externo, os elementos vazados modulam o fluxo de ar, diminuindo seu ângulo horizontal e direcionando-o para cima (Figura 18)

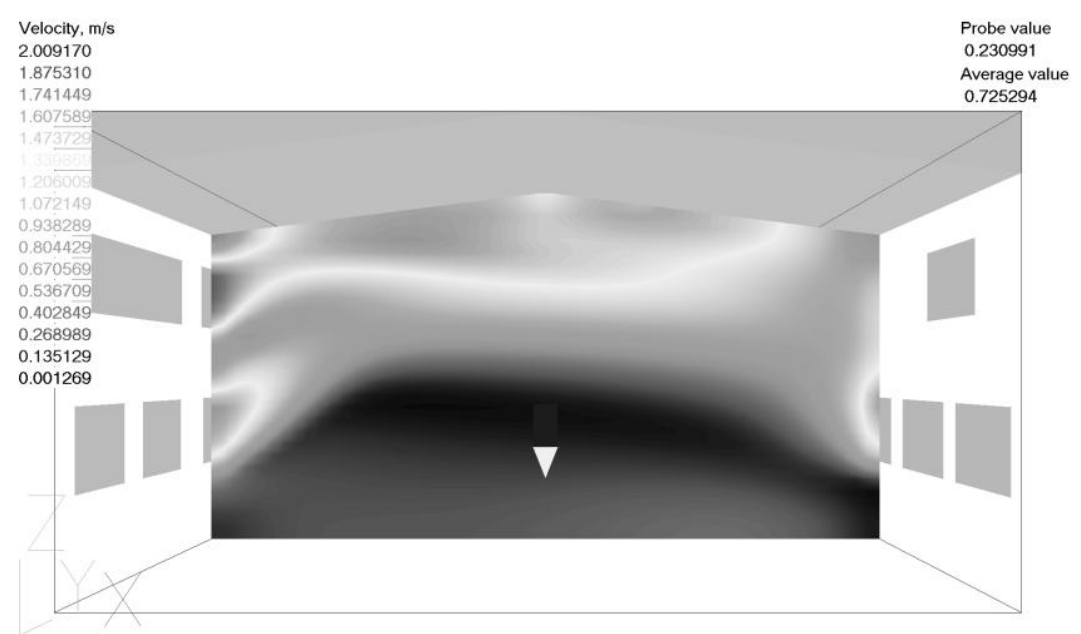

Figura 16 - Visualização dos campos de velocidade do ar para o caso-base através de contornos
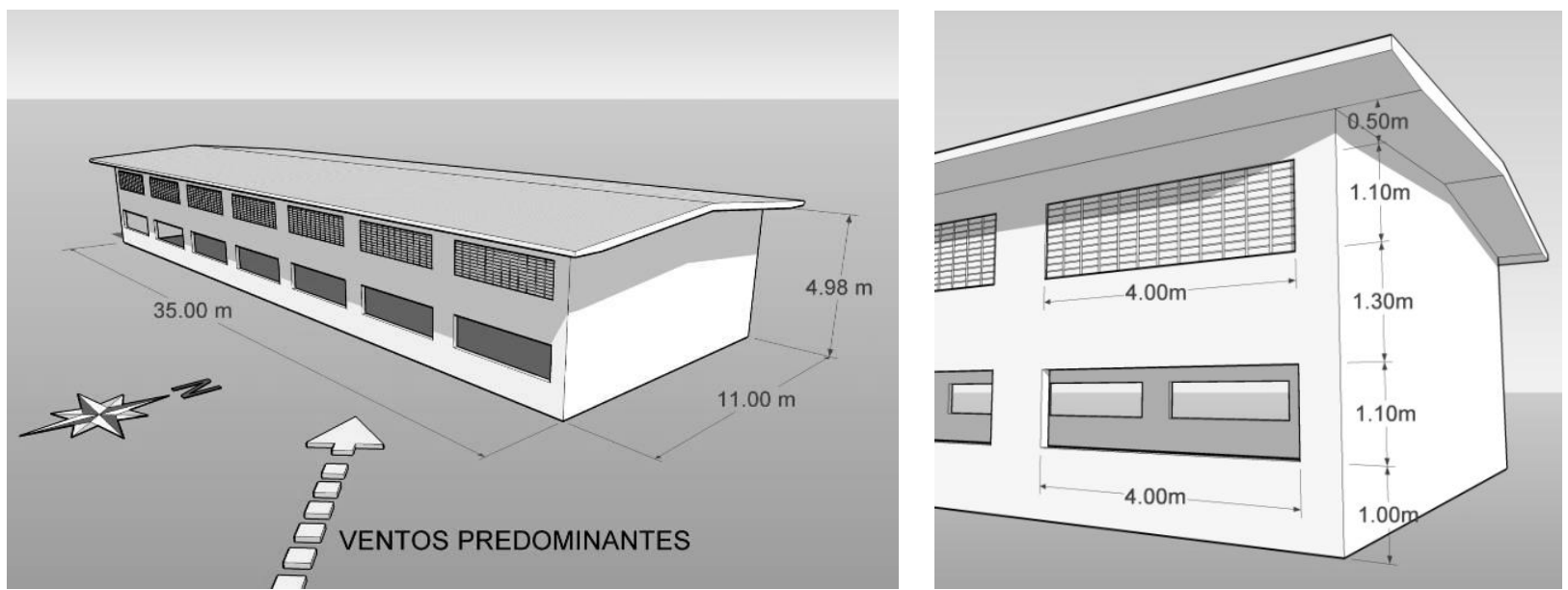

Figura 17 - Geometria do galpão otimizado
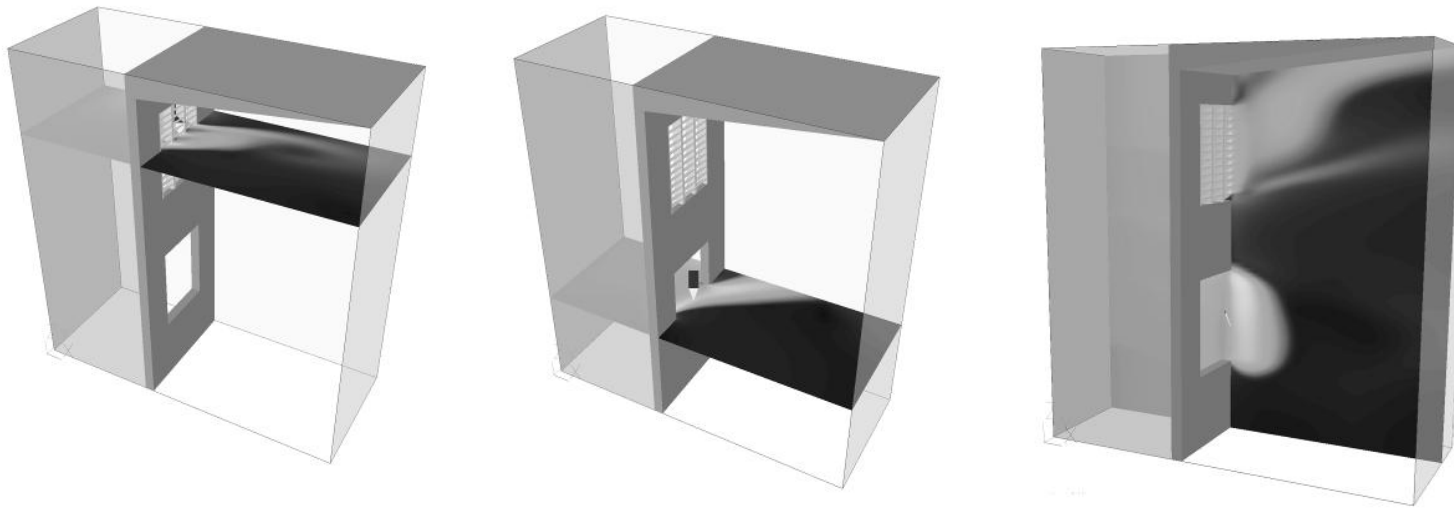

Figura 18 - Domínio reduzido do caso otimizado, com escoamento visualizado por meio de contornos 
No domínio maior foi possível confirmar não só esse comportamento como também a influência que o escoamento superior exerceu sobre o inferior. Observou-se nos campos de velocidade que o fluxo através dos elementos vazados atraiu parte dos vetores do escoamento de baixo, com formação de vórtice entre as aberturas (Figura 19).

$\mathrm{Na}$ visualização por superfícies (Figura 20), indicou-se uma distribuição mais equilibrada das velocidades de $0,5 \mathrm{~m} / \mathrm{s}$ a $1,5 \mathrm{~m} / \mathrm{s}$ em todo o interior do galpão, inclusive no nível dos usuários. Entretanto, o número de renovações de ar para esse caso foi de 151 trocas/h, apontando pouca influência das modificações na geometria das aberturas para as trocas de ar. Esse resultado pode ser atribuído às simplificações necessárias para reproduzir as aberturas por elementos vazados, que, neste caso, foram representadas pela simples diminuição da área de entrada e saída do escoamento (inlets e outlets), equivalentes à área de aberturas dos cobogós.

\section{Simulações térmicas}

\section{Análise de sensibilidade}

Foram realizadas simulações com variações da taxa de renovação de ar para avaliar a sensibilidade dos resultados de temperatura do ar. As taxas adotadas foram 10, 25, 50, 100 e 200 trocas de ar por hora, inicialmente para o caso-base. A Figura 21 mostra a comparação entre as temperaturas atingidas dentro do galpão para as diferentes trocas de ar e a temperatura externa, em função de quatro faixas distintas de sensação de conforto térmico.

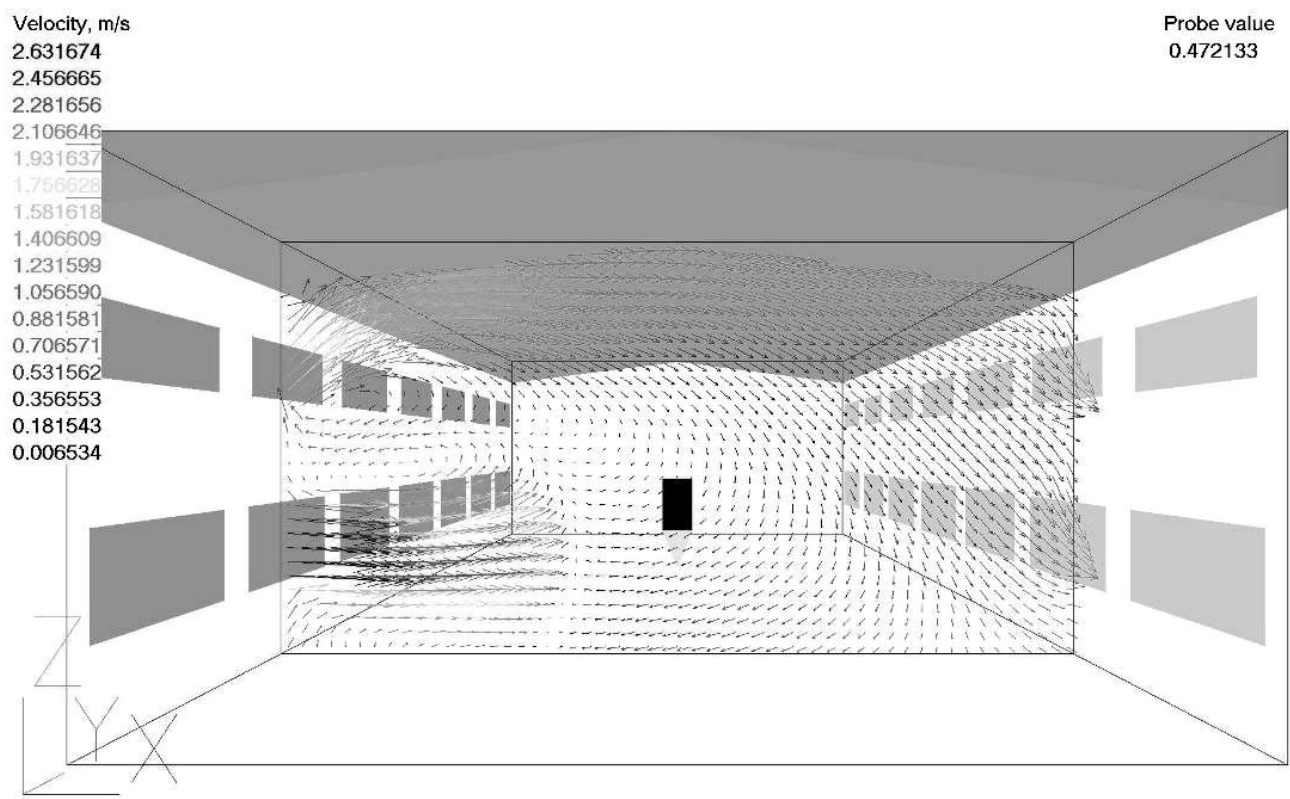

Figura 19 - Visualização dos campos de velocidades gerados pela envoltória otimizada através de vetores
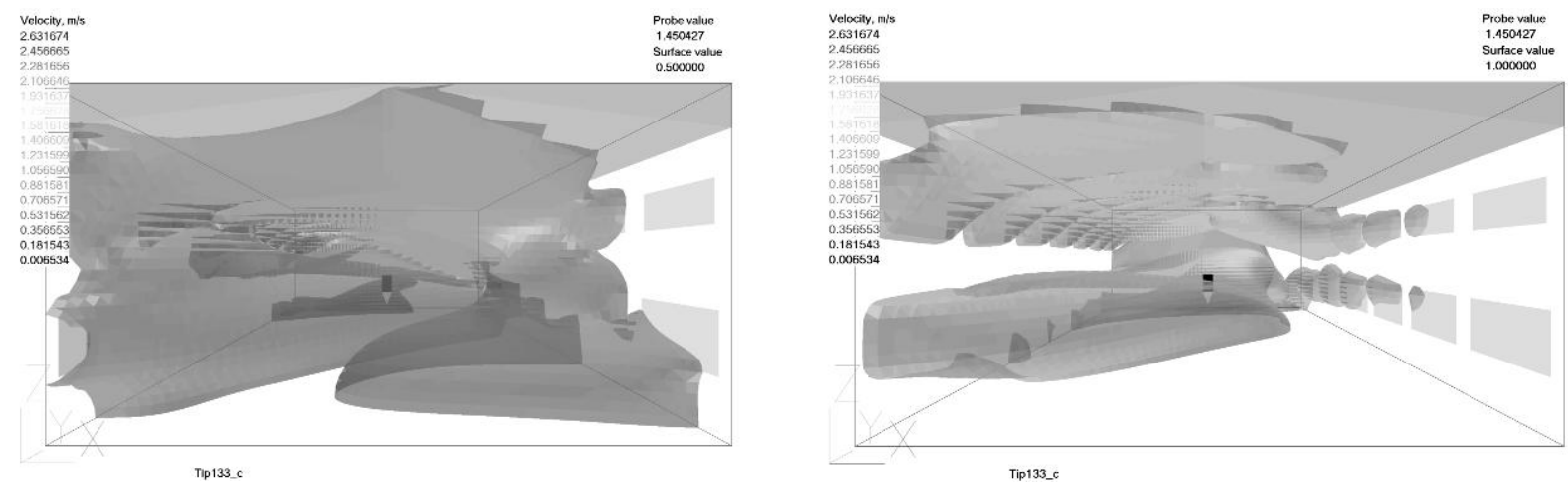

Figura 20 - Visualização das superfícies no plano X, para velocidades de $0,5 \mathrm{~m} / \mathrm{s}$ e $1,0 \mathrm{~m} / \mathrm{s}$ para o caso otimizado 


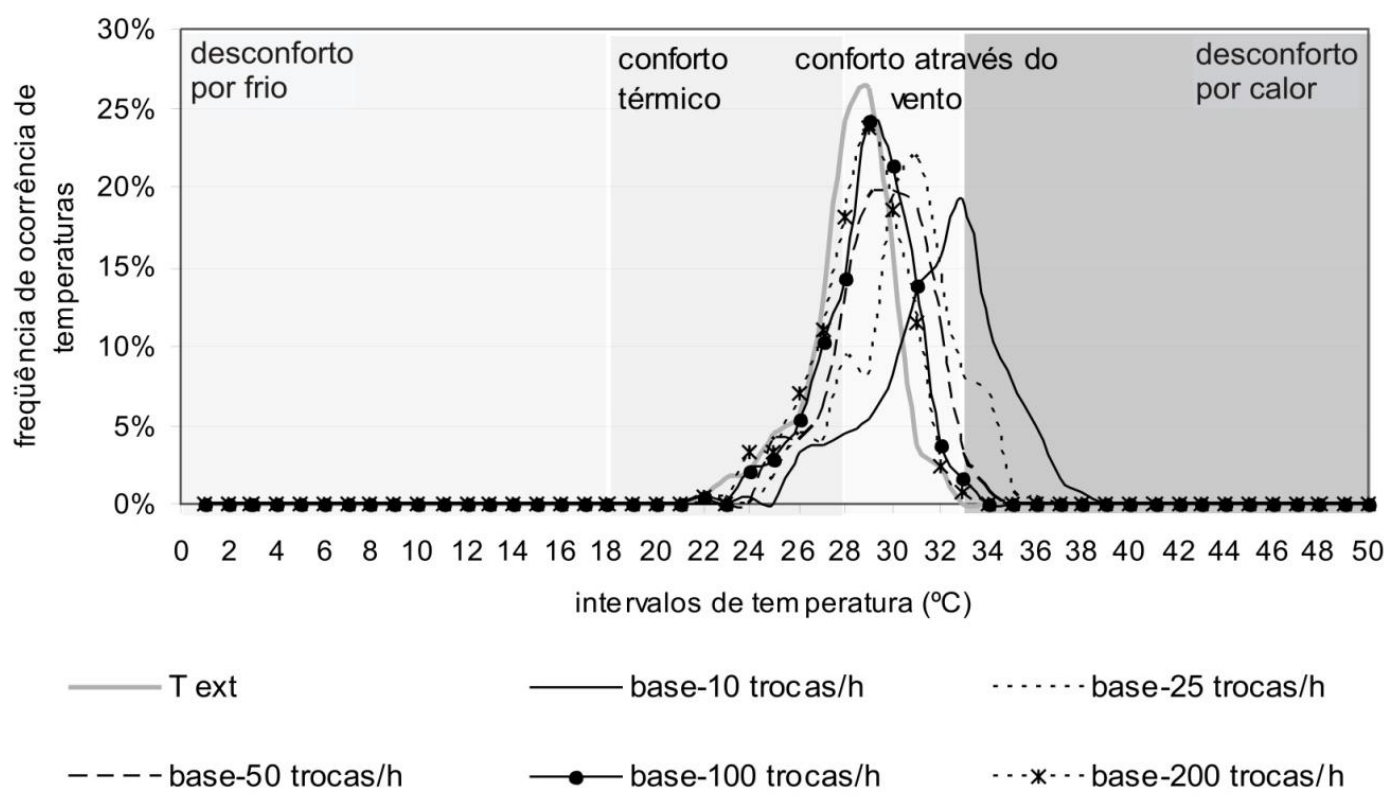

Figura 21 - Frequência de temperaturas para variações das taxas de renovação de ar

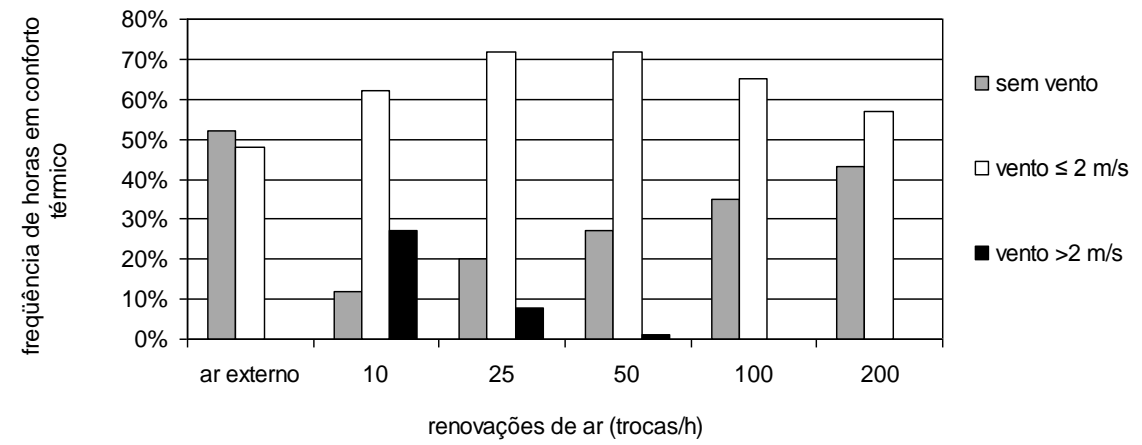

Figura 22 - Frequência de horas em conforto do caso-base para diferentes renovações de ar

Essas faixas foram distribuídas em função dos resultados da aplicação do modelo de conforto adaptativo de Humphreys, que estipula as temperaturas em que o indivíduo está em conforto sem a necessidade de ventilação e aquela na qual a ventilação é necessária, com limites médios de 280 ${ }^{\circ} \mathrm{C}$ a $33{ }^{\circ} \mathrm{C}$, para ventos de até $2,0 \mathrm{~m} / \mathrm{s}$.

A quantidade de horas ocorridas em cada faixa de conforto também pode ser avaliada no gráfico da Figura 22, que demonstra mais claramente a predominância de ocorrências de temperaturas dentro da zona de conforto com o auxílio da ventilação de até $2,0 \mathrm{~m} / \mathrm{s}$.

Com base nos resultados dos gráficos, observa-se também que:

(a) quanto maior a taxa de renovação, as temperaturas internas se aproximam das externas; (b) o efeito convectivo do ar em movimento no usuário é necessário para atender ao conforto térmico no interior da edificação; e

(c) trocas acima de 25 minimizam a ocorrência de temperaturas em que são necessárias velocidades internas acima de $2 \mathrm{~m} / \mathrm{s}$.

Também foi simulada uma versão do galpão com a envoltória otimizada, isto é, com isolamento térmico na cobertura (transmitância térmica de 0,6 $\mathrm{W} / \mathrm{m}^{2} \mathrm{~K}$ ) e cor clara (absortividade de $30 \%$ ). Essa opção foi acrescentada ao estudo como exemplo de aplicação do método de análise, e também para demonstrar a forte influência da cobertura de fibrocimento na irradiação de calor, uma vez que ela possui alta emissividade, agravada por sua pequena inclinação, sendo responsável por boa parte da sensação de desconforto térmico sentida no interior de galpões. A análise de sensibilidade demonstrou que as temperaturas internas são muito próximas às do exterior (Figura 23), confirmando 
que o isolamento da cobertura é essencial para a diminuição das temperaturas internas. Nesse caso, a redução das cargas térmicas incidentes na edificação é tão importante quanto à promoção da ventilação para se atingir o conforto térmico no interior do galpão.

\section{Influência da renovação de ar na temperatura do ar interno}

A influência na renovação de ar na mudança da temperatura do ar interno foi avaliada por meio de simulações no programa VisualDOE. Foram simulados modelos com cada uma das seis taxas de renovação obtidas por CFD, resultando nas curvas de distribuição da Figura 24. Observa-se que o aumento do número de renovações resulta em temperaturas menores.

Os resultados demonstraram que, para taxas de renovação entre 100 e 200 trocas por hora, se obtém conforto térmico sem a necessidade de promover movimento de ar acima de $2 \mathrm{~m} / \mathrm{s}$ (Figura 25). Observa-se que o impacto do aumento de renovações é maior, próximo de 100 trocas $/ \mathrm{h}$, do que para aumentos acima de 147 trocas/h.

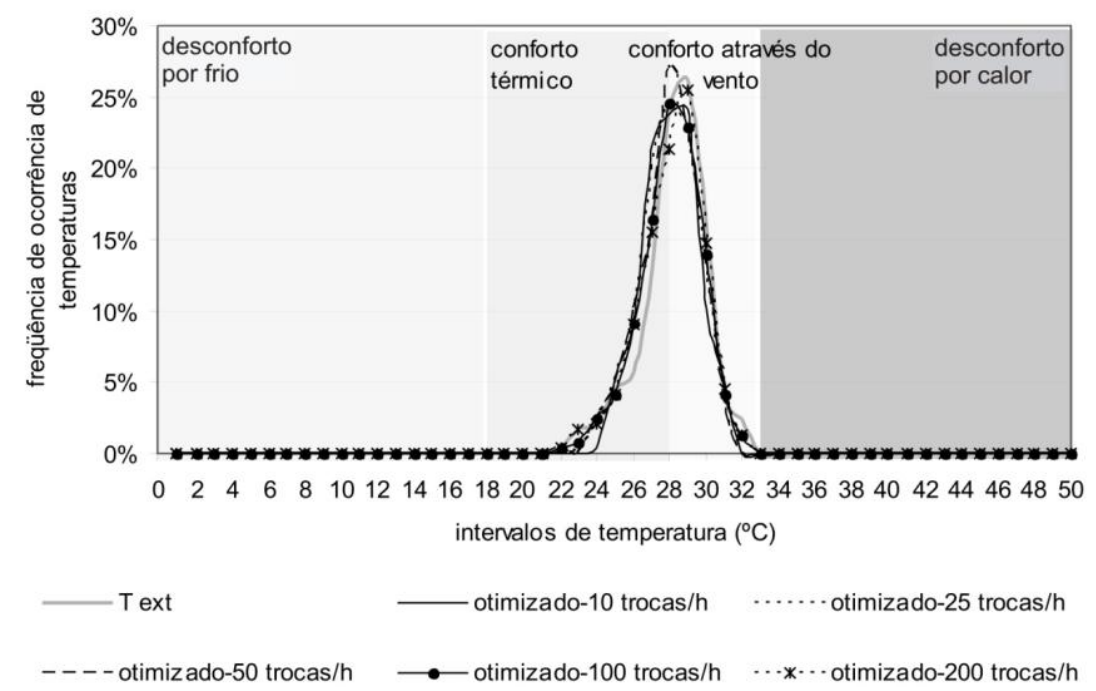

Figura 23 - Frequências de temperaturas para variações das taxas de renovação de ar para uma envoltória otimizada



Figura 24 - Gráfico de frequências de temperaturas do ar para variações de trocas de ar por hora 




Figura 25 - Frequência de horas em zonas de conforto em função das trocas de ar para casos simulados

\section{Conclusões}

A aplicação de análises do desempenho da ventilação natural através de simulações em CFD por arquitetos deve ser objeto de contínuas pesquisas e discussões para que seja incorporada ao cotidiano de um projetista.

No decorrer da pesquisa, foram necessárias simplificações para operacionalizar as abordagens, considerando as limitações das ferramentas, das fontes de dados climáticos e do próprio usuário. Os resultados encontrados mostraram a complexidade e as limitações das abordagens, pouco compatíveis com o processo projetual.

Embora a pesquisa tenha se concentrado num objeto de estudo de geometria aparentemente simples, os problemas de escala dos modelos levaram a adaptações que comprometeram a confiabilidade dos resultados e sua aplicação no suporte às decisões arquitetônicas. Além disso, a integração entre as ferramentas de CFD e térmica demandou dados climáticos diferentes, levando a questionamentos sobre o método de seleção das condições de contorno e representatividade dos resultados.

As limitações e potencialidades da metodologia são apresentadas a seguir, incluindo considerações sobre a aprendizagem do software de CFD e as fontes de incertezas dos resultados.

\section{Aprendizagem}

No início do processo, destaca-se a necessidade de material didático mais específico do que o disponibilizado. $\mathrm{O}$ aprendizado da ferramenta foi comprometido pela resumida fonte de referências específicas sobre o assunto em questão. Os tutoriais, manuais e ajudas do programa têm um caráter mais generalista e amplo, tanto em relação a sua operação, como também em relação ao entendimento dos fenômenos envolvidos nas simulações. Essa falta de especificidade da documentação inibe a exploração de seus recursos por parte de usuários com formação em arquitetura, assim como retarda as primeiras experimentações com a ferramenta. $\mathrm{O}$ suporte técnico oferecido pelo distribuidor do programa se mostrou imprescindível para conduzir o estudo, suprindo as limitações das fontes de referência.

Em seguida, o processo se caracteriza pela necessidade de conhecimentos de mecânica de fluidos e de solução numérica de equações diferenciais devido à necessidade de fornecer variáveis e parâmetros de entrada, como fatores de relaxação, modelo de turbulência, esquemas de diferenciação, variáveis de controle de solução, entre outros. Para o usuário com formação em arquitetura, o domínio da ferramenta requer mais do que informação conceitual dessas variáveis. Torna-se essencial entender seus impactos nas simulações. Essas questões não são discutidas no material de apoio, tampouco em artigos. $\mathrm{Na}$ realidade, os artigos parecem evitar a discussão dessas variáveis e procuram se concentrar nos resultados.

Muitos pesquisadores e usuários de CFD consideram que o domínio do uso da ferramenta requer experiência. Informalmente, alguns pesquisadores enfatizam a importância da intuição do usuário, que passa a dominar o programa a partir da combinação de seu conhecimento e da assimilação da resposta do programa diante dos problemas apresentados. Foram necessários anos para se atingir esse estágio, que poderia ter sido melhorado se o processo de aprendizagem fosse acelerado, de modo a se analisar um número mais expressivo de simulações.

\section{Simulação}

Após a familiarização com as principais variáveis de entrada, através da interação com outros usuários de CFD, ocorreu o período de 
aprendizagem caracterizado pelas inúmeras experimentações (e frustrações) para produzir resultados aceitáveis. As principais dificuldades foram:

(a) interface do programa: apesar dos avanços ocorridos na versão utilizada (3.6.0) em relação às anteriores, principalmente no que diz respeito à modelagem geométrica e aos comandos de visualização, o PHOENICS ainda dispõe de uma interface que exige considerável conhecimento de mecânica de fluidos e de linguagem FORTRAN. A maioria dos comandos tem suas funções atreladas a essa linguagem computacional, que, nesta última versão, também incorporou outro recurso de programação denominado PIL - PHOENICS input language;

(b) modelagem da malha: grandes diferenças de dimensões dos objetos estudados demandaram recursos de modelagem da malha, que se mostrou pouco flexível. A impossibilidade de aplicação de refino localizado comprometeu a sequência de procedimentos e a qualidade dos resultados apresentados;

(c) convergência das simulações: a questão foi motivo de muitas discussões que não puderam ser respondidas por meio de consulta à literatura, como também em ajudas e manuais do programa. Como o suporte técnico foi utilizado durante muito tempo para solucionar questões de modelagem da malha, sua duração não foi suficiente para elucidar a maior parte dos problemas relativos à convergência das simulações. Isso levou à utilização de parâmetros de configuração baseados em exemplos semelhantes encontrados na biblioteca interna do PHOENICS; e

(d) interpretação dos erros: apenas em consulta realizada ao suporte técnico, em caráter excepcional, foi possível esclarecer a questão da correta leitura dos erros residuais das variáveis envolvidas nas simulações. Até então, consideraram-se valores mostrados no gráfico de saída, que, segundo o suporte, não constituem um parâmetro adequado para análise de convergência global. A indicação da soma dos resíduos para cada variável no arquivo result demonstrou que os erros encontrados nas simulações foram mais próximos daqueles encontrados na literatura consultada.

\section{Fontes de incertezas dos resultados}

\section{Modelagem em CFD}

Houve diversas simplificações dos modelos que geraram dúvidas sobre a confiabilidade dos resultados. Nos casos dos domínios menores, por exemplo, suas dimensões reduzidas, levaram à colocação de outlets laterais e posteriores, na tentativa de simular a continuação do escoamento tanto no exterior quanto no interior do galpão. Essa aproximação deixa de considerar os reais efeitos gerados na ventilação para as duas situações, como os coeficientes de pressão da fachada em escala real. Tal simplificação resulta em um falso comportamento do fluxo de ar, já que sua condição de escoamento é declarada no programa como sendo igual nas duas situações.

No domínio construído para o galpão, também foram necessárias outras simplificações. Os inlets e outlets não puderam reproduzir as características geométricas dos elementos vazados, sendo diferenciados das aberturas livres apenas pela redução das suas dimensões, equivalentes à área livre de abertura de cobogós. Nesse caso, deixa-se de considerar as reais condições de entrada e principalmente de saída do escoamento, pois não está sendo simulada a resistência que a geometria dos elementos provoca nele. Essa simplificação pode ser a causa de o número de renovações para o caso otimizado (151 trocas/h) ter sido muito próximo do caso-base (147 trocas/h), mesmo após o aumento nas dimensões de todas as aberturas.

Detalhes da geometria do galpão também não foram modelados, como, por exemplo, beirais, divisões internas, aberturas das fachadas laterais e aberturas existentes sob as telhas, entre outros. Com isso, muitas interferências no fluxo interno deixam de ser consideradas, alterando os resultados de campos de velocidade e de renovação do ar.

É importante ressaltar que a própria ausência de transferência de calor nas simulações altera o nível de aceitação dos resultados, apesar de não inviabilizar estudos dessa natureza, como confirmou Maliska (2001).

\section{Registros climáticos}

As condições de contorno utilizadas para as simulações térmica e de ventilação natural empregam informações distintas. Enquanto o VisualDOE adota o arquivo climático TRY de 1954, as simulações em CFD se basearam em dados coletados nos anos de 2002 a 2005. A 
comparação das duas fontes por meio de suas rosas dos ventos (Figura 26) para o horário comercial evidencia que:

(a) o ano de 1954 apresenta velocidades menores do que os registros de 2002 a 2005;

(b) as medições da direção do vento do arquivo TRY apresentam intervalos maiores, tornando-se menos sensível às variações; e

(c) os modelos coincidem quanto à direção predominante do vento no quadrante sudeste, entretanto o TRY de 1954 aponta boa parte dos ventos com incidência leste, o que não ocorre na outra situação.

Outra limitação do método relacionada aos arquivos climáticos diz respeito ao período considerado nas simulações das duas ferramentas. O VisualDOE realiza a simulação térmica para o ano inteiro, enquanto o PHOENICS simula um instantâneo no tempo. Além disso, a análise térmica emprega um arquivo climático determinado por um método que ignora a frequência do vento na renovação de ar.

\section{Integração entre ferramentas}

A integração entre as ferramentas de CFD e de simulação térmica apresenta limitações que comprometem os resultados. Nesse trabalho, a renovação de ar calculada pelo CFD é declarada no programa de simulação térmica como uma constante ao longo das horas, independentemente de suas variações. Ao final da simulação térmica, apenas são analisados os resultados que correspondem àquelas faixas de velocidade $\mathrm{e}$ orientação de vento simulados no CFD. Ao fazer isso, considera-se que os demais horários não são representativos, entretanto eles certamente influenciaram os horários selecionados. $\mathrm{Na}$ realidade, deveria ser conhecida a renovação de ar a cada hora, para as muitas situações de velocidade e direção do vento. Isso é inviável operacionalmente, porém poderia ser melhorado através de formas de acoplamento entre ferramentas.

\section{Representatividade das condições de contorno}

As condições de contorno extraídas da análise das rosas de vento foram determinadas a partir de um agrupamento de ocorrências de ângulos de incidência com faixas de velocidade do ar, seguidos de uma média ponderada. Os critérios de agrupamento apenas consideraram intervalos regularmente distribuídos: o intervalo da velocidade foi de $1,0 \mathrm{~m} / \mathrm{s}$, e o da orientação foi de 36 faixas de $10^{\circ}$. Na análise dos resultados de renovações de ar, demonstrou-se que a orientação do vento influenciou mais os resultados do que a velocidade. Portanto, a determinação das condições de contorno deve considerar a sensibilidade do modelo em relação às variáveis de contorno.


Figura 26 - Rosas dos ventos para 1954 (esquerda) e para o período utilizado na pesquisa 


\section{Potencialidades do método}

Apesar das limitações, o método aponta para algumas potencialidades que podem servir de referências para o desenvolvimento de estudos mais detalhados, como:

(a) as simulações apresentaram resultados qualitativos que permitem avaliar a distribuição da ventilação no interior da edificação;

(b) a divisão das simulações de CFD em domínios separados garante a captura de detalhes geométricos que normalmente não são considerados em escalas maiores, viabilizando simulações de objetos de pequenas dimensões com menor tempo de processamento. Esse recurso foi destacado por Bittencourt (1993) como uma das vantagens do CFD em relação aos túneis de vento, que não conseguem capturar elementos de escala reduzida; e

(c) os resultados de campos de velocidade e renovações de ar certamente podem auxiliar as decisões projetuais à medida que os procedimentos se tornarem mais confiáveis e rápidos de serem obtidos.

\section{Objeto de estudo}

Os resultados das simulações, mesmo com as incertezas apontadas e o número reduzido de variações nos modelos, puderam gerar algumas considerações sobre a utilização da tipologia dos galpões pré-moldados, principalmente quanto ao emprego dos componentes construtivos e sua influência nos campos de velocidade internos e no desempenho térmico da edificação. São elas:

(a) os elementos vazados do tipo veneziana se mostraram ineficazes para a ventilação no nível do usuário por desviarem o fluxo verticalmente. Para as aberturas situadas próximo à cobertura, no entanto, o elemento pode contribuir para a remoção do calor transmitido pelo telhado;

(b) reconhece-se que para o uso em galpões prémoldados padrão, que têm suas fachadas expostas à radiação solar e à chuva, o cobogó do tipo veneziana se torna uma das poucas alternativas de fechamento que oferece proteção às intempéries, permitindo a passagem de ar constante. Isso reforça a necessidade de se investir na melhoria da envoltória de edifícios do tipo galpão, promovendo a proteção das aberturas e permitindo, assim, o uso de outros fechamentos, como esquadrias;

(c) as análises térmicas demonstraram a importância não só da ventilação, mas também da redução das cargas térmicas incidentes no interior do galpão pelas superfícies, principalmente a cobertura. Com seu isolamento térmico, conseguiuse atingir temperaturas muito próximas das externas, confirmando que as telhas de fibrocimento são responsáveis pela irradiação de grande parte do calor presente no interior dos galpões; e

(d) por fim, a pesquisa, mesmo que de forma superficial, confirmou as limitações da tipologia dos galpões pré-moldados em relação à adequação ao clima local, devido a sua envoltória ineficiente. Destacam-se como pontos negativos a precária proteção das fachadas pela ausência de beirais extensos e elementos de controle da insolação, assim como a cobertura de fibrocimento de alta transmitância térmica.

\section{Referências}

ANDERSON, John David. Computational Fluid Dynamics: the basics with applications. New York: McGraw-Hill, 1995.

ARAÚJO, Virgínia Maria Dantas de. Parâmetros de Conforto Térmico para Usuários de Edificações Escolares no Litoral Nordestino Brasileiro: o caso de Natal/RN. Natal: EDUFRN, 2001.

AUGENBROE, G. Building Simulation Trends Going Into the New Millennium. In: BUILDING SIMUlATION, 7., 2001, Rio de Janeiro. Anais... Rio de Janeiro, 2001.

\section{BLAZEK, J. Computational Fluid Dynamics:} principles and applications. Oxford: Elsevier Science, 2001.

\section{BITTENCOURT, Leonardo S. Ventilation as a} Cooling Resource for Warm Humid Climates: an investigation on the influence of geometric aspects of perforated block walls to improve ventilation inside low-rise buildings. 1993. Tese (Doutorado em Arquitetura) - Architectural Association Graduate School, Londres, 1993.

GASPAR, Pedro D.; BARROCA, Rui F.; PITARMA, R. A. Performance Evaluation of CFD Codes in Building Energy and Environmental Analisys. In: BUILDING SIMULATION, 8., 2003, Eindhoven. Anais... Eindhoven, 2003. 
GOULART, O. Dados Climáticos para Avaliação de Desempenho Térmico de Edificações em Florianópolis. 1993. Dissertação (Mestrado em Engenharia Civil) - Departamento de Engenharia Civil, Universidade Federal de Santa Catarina, Florianópolis, 1993.

HEIJMANS, N.; WOUTERS, P. Impact of the Uncertainties on Wind Pressures on the Prediction of Thermal Comfort Performances. Technical Report, Annex 35 : HybVent, Energy Conservation in Buildings and Community Systems, International Energy Agency, 2002.

HUMPHREYS, M. A. Outdoor temperatures and comfort indoors. Building Research and Practice, v. 6, n. 2, p. 92-105, 1978.

KREITH, Frank. The CRC Handbook of Thermal Engineering. Boca Raton: CRC Press, 2000.

LUDWIG, J. C.; PHOENICS. 3.6.0 Hard-Copy Documentation. PHOENICS-VR Reference Guide. London: CHAM, 2004.

MALISKA, C. R. Issues on the Integration of CFD to Building Simulation Tools. In: BUILDING SIMULATION, 7., 2001, Rio de Janeiro. Anais... Rio de Janeiro, 2001.

MENDES, N.; LAMBERTS, R.; CUNHA NETO, J. A. B. da. Building Simulation in Brazil. In: BUILDING SIMULATION, 7., 2001, Rio de Janeiro. Anais... Rio de Janeiro, 2001.

NICOL, F. Adaptive Thermal Comfort Standards in the Hot-Humid Tropics. Energy and Buildings, v. 34, n. 6, p. 529-532, 2004.

OLIVEIRA, A. G. de. Metodologia para Avaliação do Desempenho Térmico em Residências Unifamiliares no Clima Quente Úmido. 2006. Dissertação (Mestrado em Arquitetura e Urbanismo) - Programa de PósGraduação em Arquitetura e Urbanismo, Universidade Federal do Rio Grande do Norte, Natal, 2006.
PEDRINI, Aldomar. Desenvolvimento de Metodologia de Calibração de Modelos para Simulações Térmica e Energética de Edificações. 1997. Dissertação (Mestrado em Engenharia Civil) - Universidade Federal de Santa Catarina, Florianópolis, 1997.

PEDRINI, Aldomar. Integration of Low Energy Strategies to the Early Stages of Design Process of Office Buildings in Warm Climate. 2003.

Tese (Doutorado em Arquitetura) - Universidade de Queensland, Queensland, 2003.

PEDRINI, Aldomar.; SZOKOLAY, S. The Architects Approach to the Project of Energy Efficient Office Buildings in Warm Climate and the Importance of Design Methods. In: BUILDING SIMULATION, 9., 2005, Montreal. Anais... Montreal, 2005.

SPALDING, D. B. PHOENICS 3.6.0 Hard-Copy Documentation. PHOENICS Overview. London: CHAM, 2004.

VERSTEEG, H. K.; MALALASEKERA, W. An Introduction to Computational Fluid Dynamics: the finite volume method. Londres: Longman, 1995.

VISUALDOE 4.0 Media Release. San Francisco, 2004. Disponível em:

<http://www.archenergy.com/products/visualdoe>. Acesso em: 31 set. 2005.

WRPLOT View. Version 4.8.5: Lakes Environmental Software, 2004.

ZHAI, Z. J.; CHEN, Q. Y. Strategies for Coupling Energy Simulation and Computational Fluid Dynamics Pprograms. In: BUILDING

SIMULATION, 7., 2001, Rio de Janeiro. Anais... Rio de Janeiro, 2001.

\section{Agradecimentos}

Os autores agradecem à Eletrobras, pelo financiamento dos equipamentos utilizados nesta pesquisa, e à Capes, pelo apoio financeiro. 